\title{
Postreplicative Mismatch Repair
}

\author{
Josef Jiricny \\ Institute of Molecular Cancer Research, University of Zurich and ETH Zurich, 8057 Zurich, Switzerland \\ Correspondence: jiricny@imcr.uzh.ch
}

\begin{abstract}
The mismatch repair (MMR) system detects non-Watson-Crick base pairs and strand misalignments arising during DNA replication and mediates their removal by catalyzing excision of the mispair-containing tract of nascent DNA and its error-free resynthesis. In this way, MMR improves the fidelity of replication by several orders of magnitude. It also addresses mispairs and strand misalignments arising during recombination and prevents synapses between nonidentical DNA sequences. Unsurprisingly, MMR malfunction brings about genomic instability that leads to cancer in mammals. But MMR proteins have recently been implicated also in other processes of DNA metabolism, such as DNA damage signaling, antibody diversification, and repair of interstrand cross-links and oxidative DNA damage, in which their functions remain to be elucidated. This article reviews the progress in our understanding of the mechanism of replication error repair made during the past decade.
\end{abstract}

$T_{\text {the }}^{\text {h }}$ he mismatch repair (MMR) system is one of the key guardians of genomic integrity. Its malfunction leads to a substantial increase in spontaneous mutagenesis, illegitimate recombination, and cancer in mammals. MMR improves the fidelity of DNA replication by several orders of magnitude by excising sections of the nascent strand containing mispaired nucleotides. It is likely that MMR has evolved to carry out this function in order to ensure that daughter cells inherit an exact replica of the parental genome. But MMR also controls the fidelity of recombination by removing mispairs from heteroduplexes arising between donor and recipient strands and possibly even rejecting synapses between sequences that are too diverged. Indeed, the existence of MMR was first invoked in the 1960s to explain the unanticipated segregation of genetic markers in fungi and bacteria (for a comprehensive overview of the field, see chapter 12 in Friedberg et al. 1995). During the intervening 50 years, our understanding of MMR has made enormous progress; the main protagonists, as well as many "extras" that participate in this complex process, have been identified, initially in a series of genetic and biochemical experiments and later by sequence homology searches that were made possible by the high degree of evolutionary conservation of MMR. Analysis of the primary sequences of these polypeptides then helped to uncover their enzymatic activities that were confirmed by biochemical and structural studies. In vitro MMR assays using cell extracts and recombinant DNA substrates carrying single mismatches at defined positions led to the discovery of criteria required for efficient, strand-directional MMR. Finally, the Escherichia coli and the minimal

Editors: Errol C. Friedberg, Stephen J. Elledge, Alan R. Lehmann, Tomas Lindahl, and Marco Muzi-Falconi

Additional Perspectives on DNA Repair, Mutagenesis, and Other Responses to DNA Damage available at www.cshperspectives.org

Copyright (C) 2013 Cold Spring Harbor Laboratory Press; all rights reserved; doi: 10.1101/cshperspect.a012633

Cite this article as Cold Spring Harb Perspect Biol 2013;5:a012633 
J. Jiricny

human MMR systems could be reconstituted from purified recombinant proteins (Dzantiev et al. 2004). Despite this wealth of knowledge, however, we still lack detailed understanding of the molecular transactions that lead to successful repair of replication errors, and our notion of the role(s) of MMR proteins during recombination is highly speculative.

Since the discovery of a link between its malfunction and cancer (for recent reviews, see Wimmer and Etzler 2008; Hewish et al. 2010), MMR has attracted a great deal of attention, and recent progress in our understanding of this pathway has been the subject of several reviews (Stojic et al. 2004; Kunkel and Erie 2005; Iyer et al. 2006; Jiricny 2006; Hsieh and Yamane 2008; Li 2008; George and Alani 2012; PeñaDiaz and Jiricny 2012). This article therefore provides only a brief overview of the MMR process and focuses primarily on the most recent insights into this complex pathway of DNA metabolism.

\section{KEY CRITERIA FOR EFFICIENT POSTREPLICATIVE MMR}

Mismatches are defined as non-Watson-Crick base pairs or as small loops of extrahelical nucleotides that arise from slippage of the two strands with respect to each other. (These are referred to as insertion/deletion loops [IDLs], because they cause insertions or deletions in progeny DNA if left unrepaired.) Mismatches represent a unique type of "DNA damage," because they consist entirely of undamaged DNA and exist only transiently, that is, only as long as the two strands of the duplex remain annealed. Once separated, neither strand contains repairable "damage" and the passage of a replication fork through a mismatch will give rise to $50 \%$ progeny DNA containing a mutation (Fig. 1A). Thus, the first criterion for efficient MMR is that mismatches must be corrected before the next round of replication.

Replicative DNA polymerases incorporate noncomplementary nucleotides with a frequency of approximately $1: 10,000$ to $1: 100,000$ (Arana and Kunkel 2010). In theory, incorporation of any nucleotide (G, A, T, or C) opposite of any nucleotide in the template could give rise to 12 base/base mispairs, but polymerases tend to misincorporate nucleotides that generate the smallest helical distortions (Arana and Kunkel 2010). Moreover, polymerases have difficulty in extending from mispaired primer termini and thus provide proofreading exonucleases that are intrinsic to all replicative polymerases with an opportunity to remove the mispaired nucleotide from the $3^{\prime}$ end of the newly synthesized strand (Fig. 1B). This process is very efficient and increases the fidelity of replication by approximately two orders of magnitude. Thus, MMR proteins will see only replication errors that are generated by replicative polymerases and those escape the proofreading process.

IDLs represent a different case. Strand slippage in a given sequence (such as a microsatellite composed of mono-, di- or trinucleotide repeats) occurring at the end of the primer strand will most likely be processed by the proofreading exonuclease. However, slippage occurring more than four nucleotides downstream from the primer terminus may not be removed by this activity, because the end of the primer is correctly annealed and is thus an appropriate substrate for extension by the polymerase (Fig. 1C). Thus, for their repair, IDLs might rely predominantly on MMR, which would explain why MMR-deficient cells display prominent instability of microsatellite repeats, which are particularly prone to slippage. Because different types of base/base mismatches and IDLs have different structures, the second criterion for efficient MMR is that the mismatch recognition factor(s) must be able to recognize different distortions in the DNA helix.

When the mismatch recognition factor identifies a mismatch in DNA, it is presented with a problem: It does not know which strand contains the correct genetic information and which strand carries the mutation. Because it is the template (parental) strand that carriesby definition - the correct genetic information, the repair process must be directed to the error-containing nascent DNA strand (Fig. 1D). Thus, the third criterion for efficient MMR is that the repair system must be able 

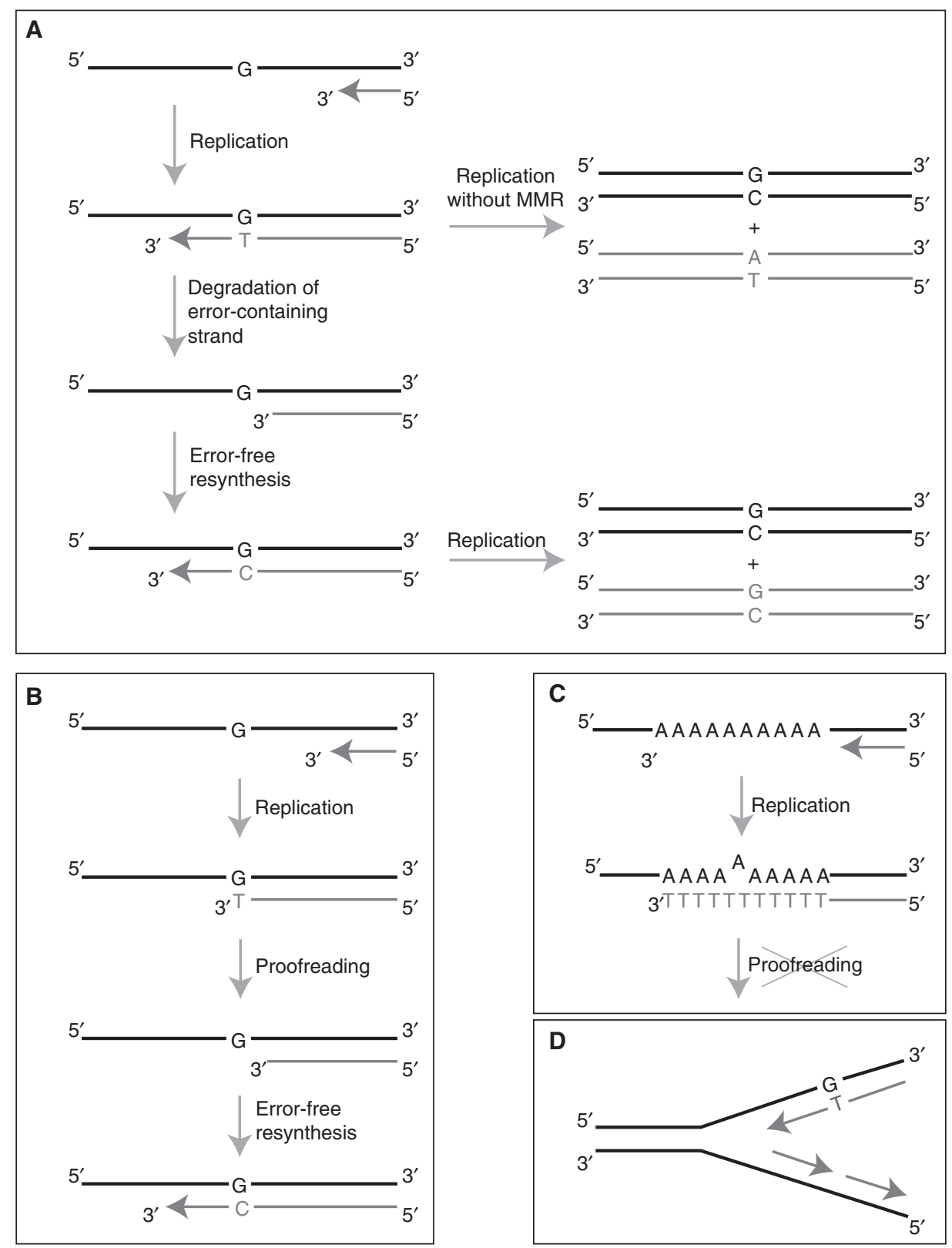

Figure 1. General scheme of replication error repair. (A) An error (in this example, G/Tmismatch) generated by a DNA polymerase during replication must be repaired before the following round of replication. Unrepaired mismatches are fixed as errors in 50\% progeny DNA (top right). MMR-mediated repair involves excision of a tract of the nascent strand (gray) that includes the misincorporated nucleotide and resynthesis of the excised tract. (B) DNA polymerases can generate 12 possible mispairs. Because these cause a misalignment between the primer terminus and template strand, incorporation of the next nucleotide (particularly, the attack of the $3^{\prime} \mathrm{OH}$ of the primer terminus on the $\alpha$ phosphate of the incoming deoxyribonucleotide triphosphate [dNTP]) is inefficient. This kinetic barrier allows for translocation of the primer terminus from the polymerase active site to its proofreading exonuclease site, which removes several nucleotides from the primer such that it can realign with the template. Mispairs that escape proofreading are substrates for MMR. $(C)$ Slippage of the primer strand in a repetitive sequence such as a microsatellite will generate an IDL (in this example, a single extrahelical A). If this structure arises behind the polymerase, it will not be detected by the proofreading exonuclease and its repair is thus entirely dependent on MMR. (D) MMR must be directed to the nascent DNA strand that carries-by definition - the erroneous genetic information. In this example, the G/T mismatch must be corrected to G/C. 
J. Jiricny

to distinguish between parent and daughter strands and direct the repair to the latter.

Much of our understanding of MMR could be gleaned from studies of model organisms such as bacteria and the yeast Saccharomyces cerevisiae, because this complex process is highly conserved in evolution-it is present in all living organisms, with the exception of Actinobacteria, Mollicutes, part of Archaea, and some bacteria (e.g., Mycobacterium tuberculosis, Helicobacter pylori) that appear to have lost this process (Sachadyn 2010). These studies revealed that all MMR systems studied to date satisfy the above criteria, albeit in slightly divergent ways that may have to do with the habitat of the given organism or the size of its genome. The latter aspect is particularly important; as mentioned above, MMR proteins are also involved in the control of recombination and other processes of DNA metabolism. A single set of MMR proteins may be sufficient to guarantee efficient repair of replication errors and keep illegitimate recombination at bay in organisms with small genomes, but organisms with large genomes may require more specialized systems to deal with phenomena such as diploidy, cell cycle, or DNA packaged in chromatin. It is therefore not surprising that eukaryotic genomes encode not only prototypic MMR proteins that function in the correction of replication errors but also paralogs that have specialized roles in recombination and other processes.

This article focuses on the repair of replication errors, which involves three steps: mismatch recognition, degradation of the errorcontaining strand, and error-free resynthesis of the repair tract. The first stage of this complex repair process involves MutS and MutL proteins, which recruit several other polypeptides, exonucleases, polymerase(s), and other replication factors for the latter two repair stages (Table 1).

\section{MUTS AND ITS HOMOLOGS IN MISMATCH RECOGNITION}

The prototypic mismatch recognition factor is the MutS protein of E. coli ( $\mathrm{Su}$ and Modrich 1986). To date, more than 300 amino acid sequences could be identified in the genomes of 169 species that contain motifs characteristic of this protein family. These polypeptides contain a highly conserved carboxy-terminal ATPase domain characteristic of ABC (ATP-binding cassette) ATPases. They can be subdivided into five groups (Sachadyn 2010), of which group 1 (MutS1) contains all proteins involved in MMR. Group 2 proteins act as suppressors of homologous recombination (Pinto et al. 2005) that bind and cleave branched DNA structures (Fukui et al. 2008). Members of the remaining

Table 1. MMR factors and their functions

\begin{tabular}{|c|c|c|}
\hline E. coli & Eukaryotes & Function \\
\hline \multirow[t]{2}{*}{ MutS } & MutS (MSH2-6) & Mismatch recognition \\
\hline & MutS (MSH2-3) & \\
\hline \multirow[t]{3}{*}{ MutL } & MutL (MLH1-PMS2) & Molecular matchmaker; strand-specific endonuclease, \\
\hline & MutL (MLH1-PMS1) & termination of excision \\
\hline & MutL $\gamma($ MLH1-3) & \\
\hline MutH & & Strand-specific endonuclease \\
\hline UvrD (MutU) & & DNA helicase \\
\hline ExoI, ExoVII & & $3^{\prime}-5^{\prime}$ Exonuclease; mismatch excision \\
\hline ExoX, RecJ & EXO1 & $5^{\prime}-3^{\prime}$ Exonuclease; mismatch excision \\
\hline Pol III Holoenzyme & Pol & Repair synthesis \\
\hline$\beta$ clamp & PCNA & Molecular matchmaker; repair synthesis \\
\hline$\gamma$ Complex & RFC & $\begin{array}{l}\beta \text {, respectively, PCNA loading; } 3^{\prime} \text { nick-directed repair; } \\
\text { activation of MutL } \alpha \text { endonuclease }\end{array}$ \\
\hline \multirow[t]{3}{*}{ Ssb } & RPA & Single-stranded DNA-binding protein; repair synthesis \\
\hline & HMGB1 & Accessory protein; stimulated excision \\
\hline & PARP & Accessory protein; improved mismatch selectivity \\
\hline
\end{tabular}


three groups have as yet no known function. This section focuses on the polypeptides involved in MMR.

Prokaryotic MutS proteins function as homodimers that are associated at their carboxyl termini such that their ATP-binding domains are partially intertwined. Structural studies showed that E. coli (Lamers et al. 2000) and Thermus aquaticus (Obmolova et al. 2000) MutS protein subunits encircle mismatch-containing oligonucleotide duplexes (Fig. 2A) but that they bind in an asymmetric manner, inasmuch as only one subunit contacts the mismatch (for review, see Kunkel and Erie 2005; Jiricny 2006). The latter contact is mediated by a phenylala- nine within a highly conserved amino-terminal motif GxFxE (found only in MutS1 group of proteins) that inserts into the duplex and stacks onto one of the mispaired bases, thus inducing a $60^{\circ}$ bend in the DNA (Fig. 2D). The stacking interaction is stabilized by the conserved glutamate that forms a hydrogen bond with $\mathrm{N}^{7}$ or $\mathrm{N}^{3}$ atoms of the mispaired purine or pyrimidine, respectively (Natrajan et al. 2003). The asymmetry is not restricted to mismatch binding; in the crystal of E. coli MutS, the subunit contacting the mismatch had an ADP molecule bound in the ATP-binding site, whereas the other site was unoccupied (Fig. 2A). Although this was not so in the case of the T. aquaticus ortholog, the
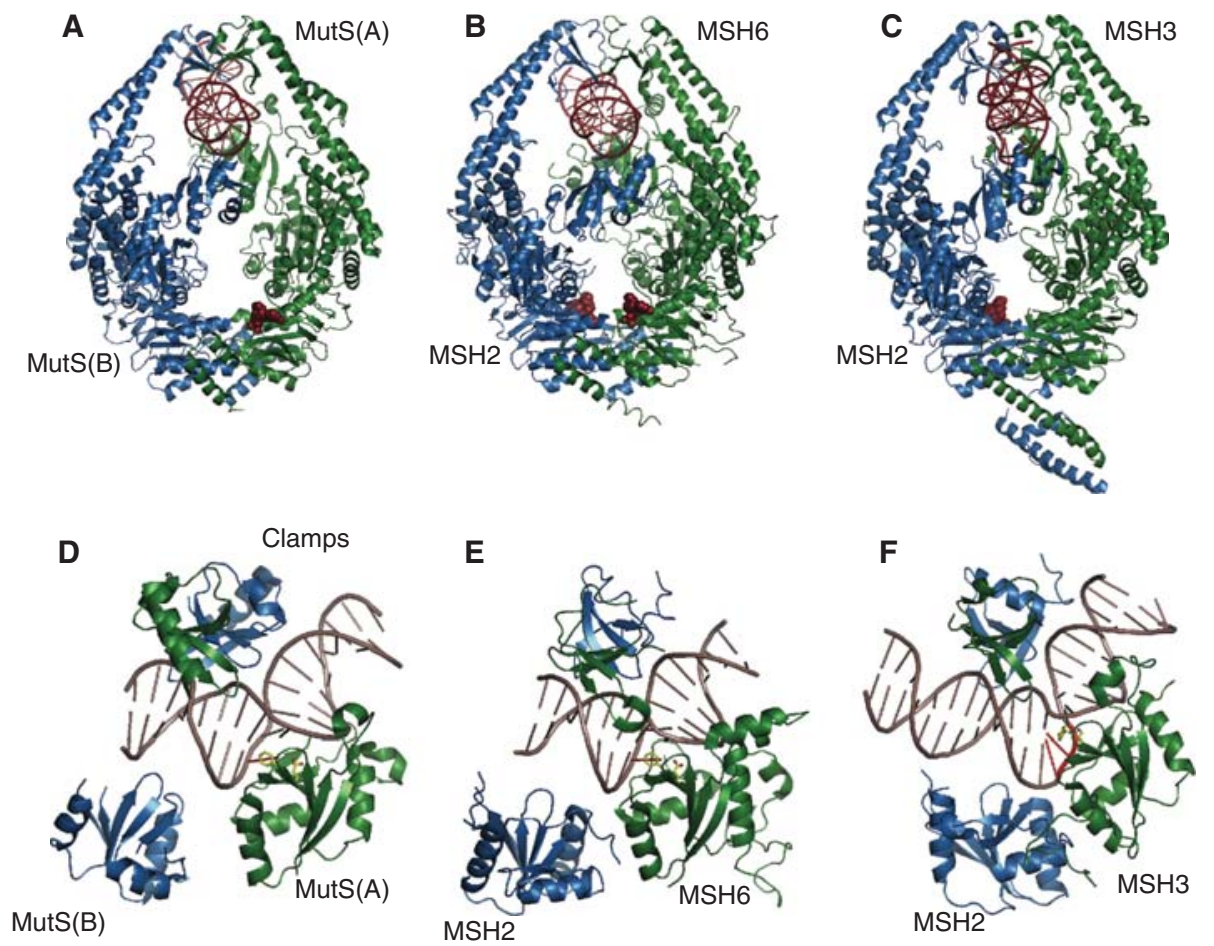

Figure 2. Comparison of overall fold and lesion recognition of E. coli MutS (A, D; 1E3M.pdb), human MutS $\alpha$ (B, E; 2O8B.pdb), and human MutS $\beta$ (C, F; 3THY.pdb). (A-C) Ribbon representations of the overall structures. The subunit directly recognizing the DNA mismatch or IDL (subunit A in E. coli MutS, MSH6 in MutS $\alpha$, or $\mathrm{MSH} 3$ in MutS $\beta$ ) is shown in green; the other subunit (Subunit B, MSH2) is shown in blue. DNA and bound ADP cofactors are depicted in dark red. $(D, E)$ E. coli MutS and human MutS $\alpha$ bind DNA containing a G/T mismatch between their nonspecific clamps and mismatch-binding domains by inducing a $60^{\circ}$ kink in the DNA and interacting with the mismatched bases (red) via conserved phenylalanine and glutamate residues (side chains in yellow). (F), Human MutS $\beta$ binds DNA containing a two-residue insertion by introducing a $90^{\circ}$ kink in the DNA and forming specific interactions with the DNA loop (red) using a lysine and a tyrosine (side chains in yellow). (Figure created using PyMOL [http://www.pymol.org].) 
J. Jiricny

composite ATP-binding sites of both MutS proteins were shown to be nonequivalent in the DNA-bound form (Junop et al. 2001; Lamers et al. 2003, 2004). Free E. coli MutS in solution can occupy both ATP-binding sites (Bjornson and Modrich 2003; Monti et al. 2011), one with ADP and the other with a nonhydrolyzable ATP analog (and thus, most likely, ATP in vivo), although this may vary from species to species or change after DNA binding.

The functional asymmetry of prokaryotic MutS homodimers was cemented by evolution: In eukaryotes, MutS homologs (MSHs) function as heterodimers. (The mitochondrial MSH1 protein of $S$. cerevisiae may represent an exception, because the purified recombinant protein was shown to bind heteroduplex substrates in vitro [Chi and Kolodner 1994] and is thus most likely a homodimer.) Of the eight eukaryotic MSH polypeptides discovered to date (Sachadyn 2010), MSH1, 6, 7, and 8 contain the GxFxE motif required for mismatch recognition. No biochemical information is available on MSH8, but MSH6 and 7 interact with $\mathrm{MSH} 2$ to form the heterodimers MutS $\alpha$ and MutS $\gamma$, respectively. MutS $\alpha$, the crystal structure of which (Fig. 2B) closely resembles MutS in its DNA-bound form (Warren et al. 2007), recognizes bases/base mismatches and IDLs of 1-2 nucleotides with the help of the conserved phenylalanine in the MSH6 subunit (Fig. 2E). In gel-shift assays, the strongest-bound substrates carry a 1-nucleotide IDL. Of base/base mismatches, only the G/T substrate is bound with appreciable affinity in gel-shifts (Jiricny et al. 1988a); this gave the protein its first acronym, GTBP (G/T-binding protein). The Arabidopsis thaliana $\mathrm{MSH}$ / MSH7 protein bound more strongly to $\mathrm{C} / \mathrm{G}$ and $\mathrm{G} / \mathrm{A}$ substrates and almost undetectably to the +1 IDL in this assay (Wu et al. 2003). However, the relative affinities determined by gel-shift studies must be interpreted with caution; the assay detects preferentially protein/DNA complexes with slow $k_{\text {off }}$, whereas even transiently bound mispairs may persist long enough to trigger MMR. Moreover, mismatch binding in vitro is strongly influenced by neighboring sequence context (Jiricny et al. 1988b; Mazurek et al. 2009). Indeed, in in vitro MMR systems, all base/base mismatches with the exception of C/C are repaired efficiently (Su et al. 1988; Huang and Crothers 2008).

The ability to deploy several MSH proteins in different combinations endows the eukaryotic MMR system with greater versatility. Thus, larger IDLs are recognized by $\mathrm{MSH}$ /MSH3, referred to as MutS $\beta$. MSH3 is a MutS ortholog that lacks the conserved GxFxE motif but is able to mediate the repair of a subset of small IDLs and even some mismatches, at least in $S$. cerevisiae (Harrington and Kolodner 2007). It is also involved in the processing of branched structures (Surtees and Alani 2006), doublestrand break (DSB) repair (Sugawara et al. 1997), and expansion of triplet repeats (for review, see Peña-Diaz and Jiricny 2012). Mutagenesis of the predicted amino terminal mismatch-binding domain of MSH3 showed that the protein may deploy two different modes of lesion recognition, because some mutations selectively affected processing of small IDLs, whereas others were deleterious for DSB repair (Dowen et al. 2010). The molecular basis for this differentiation has recently been clarified by the crystal structure of human MutS $\beta$ bound to IDLs of varying size (Gupta et al. 2012). MSH3 lacks the phenylalanine residue that, in MSH6, inserts into the DNA helix and stacks against the mispaired nucleotide. Instead, MSH3 has several basic and polar amino acids that interact with the sugar-phosphate backbone of the IDL (Fig. 2C,E). This gives it the ability to bind to IDLs of varying size. Interestingly, the MSH2 subunit, which does not participate in mismatch binding in MutS $\alpha$, contacts the larger IDLs in MutS $\beta$. These findings help to explain the phenotype of $S$. cerevisiae MutS $\beta$ variants mutated in this region (Lee et al. 2007; Shell et al. 2007a).

Whereas the amino termini of MSHs have key roles in lesion recognition (Malkov et al. 1997; Dufner et al. 2000; Lee et al. 2007; Shell et al. 2007a; Sachadyn 2010), the carboxy-terminal ATPase domains govern the next stages of MMR. The occupancy of the composite ATPbinding sites and the role of ATPase have been the subject of extensive studies during the past 15 years. This topic deserves such attention 
because it is one of the key steps of MMR. Early experiments showed that the mismatch-bound MSHs undergo an ATP-driven change in conformation that converts the protein into a sliding clamp capable of diffusing along the DNA contour and that would therefore necessitate the removal of the phenylalanine "ratchet" from the mismatch site (for review, see Jiricny 2006). This dynamic event is difficult to monitor by X-ray crystallography, but soaking ATP into the MutS/ DNA crystal caused a contraction of the carboxyl termini that could trigger such a step (Lamers et al. 2004). Kinetic studies (Martik et al. 2004; Mazur et al. 2006; Hargreaves et al. 2010; Zhai and Hingorani 2010; Heinen et al. 2011), deuterium exchange mass spectrometry (Mendillo et al. 2010), and native mass spectrometry (Monti et al. 2011) analysis of both wild-type and mutant proteins confirmed the nonequivalence of the two ATPase activities demonstrated earlier. Thus, in free proteins, the MSH6 and MSH3 subunits were shown to contribute more than MSH2 to the total ATPase activity of MutS $\alpha$ (Alani et al. 1997; Iaccarino 1998; Studamire et al. 1998; Tian et al. 2009) and MutS $\beta$ (Owen et al. 2009). Although ATPase was seen to be stimulated by several different DNA substrates (Blackwell et al. 1998; Dufner et al. 2000), detailed analysis revealed that MutS $\alpha$ ATPase is inhibited immediately after heteroduplex binding (Antony and Hingorani 2003; Mazur et al. 2006; Heinen et al. 2011). This inhibition may be linked to a compaction of the composite ATPbinding sites after substrate binding and ADP $\rightarrow$ ATP exchange (Lamers et al. 2004; Mendillo et al. 2010). In a complex in which ATP hydrolysis is inhibited by mismatch binding, both binding sites might become occupied by ATP; this could bring about the conformational change required to release the protein from the mismatch in the form of a long-lived sliding clamp (Heinen et al. 2011; Monti et al. 2011).

Recently, single-molecule studies using fluorescently labeled MutS (Cho et al. 2012; Qiu et al. 2012) and yeast MutS $\alpha$ (Gorman et al. 2007) provided convincing evidence that the proteins indeed travel along the DNA contour. After substrate binding, both DNA (Sacho et al. 2008) and the protein (Qiu et al. 2012) were seen to undergo several distinct conformational changes that were dependent on the DNA substrate and the nucleotide cofactor. On the basis of these findings, it was proposed that MutS and its orthologs form a loose clamp around the DNA and travel along the helix by lateral, corkscrew-like movement. During this phase, ATP is bound and hydrolyzed by both subunits. When the protein detects a mismatch (possibly by its perturbed stacking and hydrogen bonding interactions), it pauses and bends the DNA, and this conformational change brings about a rapid ADP to ATP exchange and concomitant inhibition of ATP hydrolysis. In the ATP-bound form, the protein retracts the phenylalanine "ratchet" out of the helix and diffuses freely along the helix (Fig. 3) (Cho et al. 2012). A similar mechanism was proposed for MutS $\beta$ (Gupta et al. 2012).

As discussed above, mismatch- and ATP-activated MSH sliding clamps leave the mismatch site in vitro. This could serve two purposes: (1) It would vacate the mismatch and thus allow the loading of further MSH clamps (Jeong et al. 2011, and references therein), and (2) the clamps diffusing away from the mismatch could recruit downstream repair factors to the sites where the excision process initiates or activates factors that might be bound there. It had been suggested that the repairosome assembles at the mismatch and interacts with the factors bound at the initiation site through space (Wang and Hays 2003, 2004), but these findings contradict data from another laboratory (Pluciennik and Modrich 2007) that used a similar system. Thus, with the recent support from single-molecule studies discussed above (Gorman et al. 2007; Cho et al. 2012), the sliding model is gaining general acceptance.

\section{MutL AND ITS HOMOLOGS}

The MutL protein and its homologs belong to a GHKL (gyrase II/Hsp90/histidine kinase/ MutL) family of ATPases that form homodimers or heterodimers through their carboxyl termini and that are believed to encircle the DNA helix through dimerization of the nucleotide-bound amino-terminal ATP-binding domains (Fig. 4) 
J. Jiricny
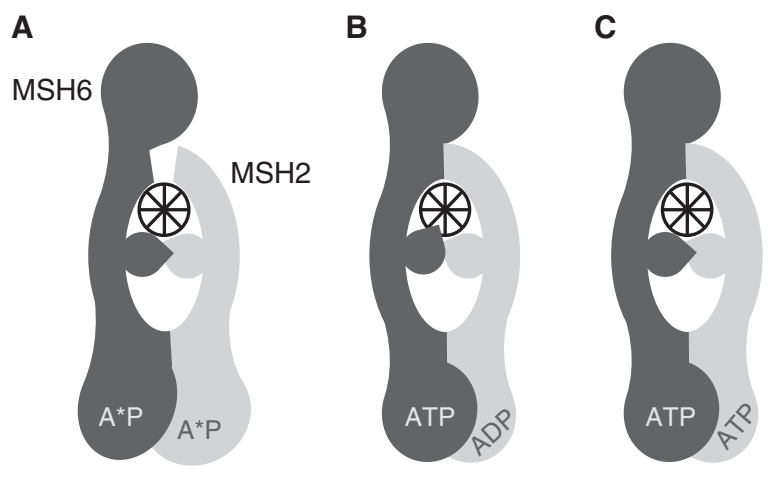

Figure 3. Putative conformations of $\mathrm{MutS} \alpha$, viewed down the longitudinal axis of the DNA helix (shown as a cartwheel). (A) On homoduplex DNA, MutS $\alpha$ is loosely bound and follows the winding of the helix. It slowly hydrolyzes ATP, and both subunits can be occupied by either ADP or ATP (shown as A*P). (B) After mismatch detection, the phenylalanine and glutamate of the GxFxE insert into the helix at the mismatch site (shown as rotation of the MSH6 "ratchet" into the DNA). This conformational change triggers an ADP-ATP exchange in MSH6 accompanied by ATPase inhibition. $(C)$ A similar exchange in the MSH2 subunit causes a withdrawal of the ratchet from the DNA. This long-lived clamp is free to slide along the DNA contour.

(see Guarné 2012 for a comprehensive review). When the homodimeric E. coli MutL protein was first purified and characterized (Grilley et al. 1989), it appeared to be devoid of DNAbinding activity, but it could be shown to substantially increase the DNaseI footprint of MutS on mismatch-containing DNA in the presence of ATP. Since this time, and because the existence of a ternary MutS/MutL/heteroduplex complex has also been substantiated in other laboratories (see, e.g., Acharya et al. 2003; Winkler et al. 2011), it has been assumed that the ternary complex formation immediately follows the binding of MutS to the mismatch and its conversion to a sliding clamp. The situation appears to be similar also in higher organisms.

There are several MutL homologs (MLHs) in eukaryotes. In human cells, the prevalent MLH homolog that participates in MMR is a heterodimer of MLH1 and PMS2 referred to as MutL $\alpha$. In S. cerevisiae, MutL $\alpha$ is composed of MLH1 and PMS1 (ortholog of human PMS2). There are two other MLH heterodimers in human cells: MLH1/PMS1, referred to as MutL $\beta$ (Räschle et al. 1999), which has to date no known function, and MutL $\gamma$ (MLH1/MLH3), which can partially compensate for the lack of MutL $\alpha$ in vitro (Cannavo et al. 2005). S. cerevisiae MutL $\gamma$ (MLH1/MLH3) also partici- pates in MMR to some extent by correcting a small subset of IDLs (Flores-Rozas and Kolodner 1998; Nishant et al. 2008), possibly redundantly with another MLH heterodimer, MLH1/ MLH2 (Harfe et al. 2000). However, the primary function of MutL $\gamma$ in yeast and mammals lies
A

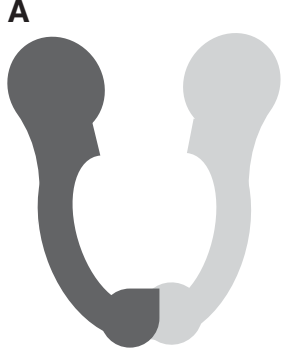

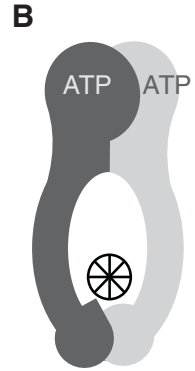

Figure 4. Putative conformations of MutL and its homologs. (A) The proteins are dimerized via their carboxy-terminal domains. (B) DNA binding causes dimerization of the amino-terminal ATPase domains, such that the protein may encircle the helix. For MutL endonucleases, the conformational change accompanying this process may poise the nuclease domain of one of the MutL subunits for cleavage of the sugar-phosphate backbone of the DNA while blocking the nuclease site of the second subunit. (In MutL $\alpha$, only the PMS subunits harbor nuclease activity.) Cleavage requires activation through interaction with $\beta$ or PCNA. 
in meiotic recombination (Lipkin et al. 2000, 2002; Nishant et al. 2008); it physically interacts with MSH4/MSH5 (Santucci-Darmanin et al. 2002), and mutants in MLH3, MSH4, and MSH5 genes have similar phenotypes (de Vries et al. 1999; Kneitz et al. 2000; Lipkin et al. 2002). In all these complexes, the two subunits are held together by their respective carboxy-terminal domains.

MutL $\alpha$ alone undergoes a series of conformational changes after ATP binding (Sacho et al. 2008), and it has been predicted that, like MutL, the protein encircles DNA, whereupon the amino-terminal ATP-binding domains dimerize (for review, see Guarné 2012). Also like bacterial MutL, eukaryotic MutL $\alpha$ heterodimers form ternary complexes with heteroduplex DNA and MutS $\alpha$ in the presence of ATP (Blackwell et al. 2001; Räschle et al. 2002; Mendillo et al. 2009). Unfortunately, we know much less about these complexes than about the MSH/heteroduplex/ ATP species. It is not clear, for example, whether the ternary complex forms while MutS $\alpha$ is bound at the mismatch or whether MutS $\alpha$ / MutL $\alpha$ interact on homoduplex DNA once the MutS $\alpha /$ ATP sliding clamp has formed and left the mispair. However, MutL $\alpha$ is not required for mismatch-bound MutS $\alpha$ to undergo the ATP-driven conformational change, because it is dispensable for a subset of repair events (see below). This would argue in favor of a model where the mismatch-bound MSHs bind ATP, change conformation to the longlived sliding clamp, and only then associate with MLHs. Whether the ternary complex diffuses along the DNA contour as freely as the $\mathrm{MSH} /$ heteroduplex/ATP complex has not yet been extensively investigated, although surface plasmon resonance experiments detected species that were trapped on heteroduplex substrates when their ends were blocked (Blackwell et al. 2001; Mendillo et al. 2005), which could be taken as evidence that the ternary complex can leave the mismatch like the MSH/ATP sliding clamp. It is hoped that new technologies, such as single-molecule studies (Gorman et al. 2007, 2010; Jeong et al. 2011), will provide novel insights into the dynamic properties of these complexes.
Why do MSHs need to associate with MLHs? In early studies, E.coli MutL was described as a "molecular matchmaker" due to its propensity to interact with other proteins. It was believed to mediate the dialog between the mismatchactivated MutS and the strand-discrimination and excision machineries. This passive role may apply to the most-studied system, E. coli. But the discovery of a MutL $\alpha$ endonuclease activity (Kadyrov et al. 2006), which is absent in the E. coli protein, brought MLHs to the forefront of MMR (Guarné 2012).

\section{DEGRADATION OF THE ERROR- CONTAINING STRAND}

As mentioned in the introduction, the mismatch-recognition complex must signal the presence of a mismatch to downstream factors located at (or recruited to) sites where the nascent and template strands can be distinguished from one another. What and where are these sites? In 1986, Claverys and Lacks postulated that MMR in Streptococcus pneumoniae might be directed to the newly synthesized strand by transient discontinuities such as gaps between Okazaki fragments (Claverys and Lacks 1986), which required the MMR system to be closely coupled to replication. This hypothesis could be supported by evidence documenting interactions between prokaryotic MutS and MutL and the $\beta$ clamp ( $\beta$ ), a processivity factor of replicative polymerase III (López de Saro et al. 2006; Simmons et al. 2008). Similarly, MutS $\alpha, \beta$ (Flores-Rozas et al. 2000; Kleczkowska 2001), and MutL $\alpha$ (Lee and Alani 2006; Iyer et al. 2010) bind proliferating cell nuclear antigen (PCNA), which has a similar role in eukaryotes. The homodimeric $\beta$ clamp and homotrimeric PCNA are loaded onto DNA at free $3^{\prime}$ termini by the $\gamma$ complex of polymerase III or by replication factor C (RFC), respectively, and form circular sliding clamps around the DNA that help to anchor polypeptides that interact with them on their respective substrates. Most replication and repair factors dock with these processivity clamps through highly conserved sequence motifs (Dalrymple et al. 2001; Warbrick 2006), and MMR proteins are no exception. The interactions 
J. Jiricny

between the polymerase processivity clamps and MSHs are essential for MMR in vivo (López de Saro et al. 2006; Shell et al. 2007b; Simmons et al. 2008) and in vitro (Pluciennik et al. 2009, 2010), but what is their function?

One possibility is that $\beta$ or PCNA recruits MMR proteins to the replication fork. Human MutS $\alpha$ colocalizes with PCNA foci in S-phase cells (Kleczkowska 2001) and most recent evidence suggests that the same is true in S. cerevisiae (Hombauer et al. 2011). In contrast, $\beta$ of Bacillus subtilis formed foci in vivo only after treatment with 2-aminopurine, a known inducer of mispairing, that prompted the suggestion that bacterial $\beta$ stabilizes mismatch-bound MutS (Simmons et al. 2008). This argued that rather than being integral members of the replication machinery, association of MSHs and MLHs with $\beta$ or PCNA may be required for downstream steps of MMR that require processive DNA synthesis. This was substantiated in the human in vitro system (Iyer et al. 2008), except for the fact that PCNA was reported to be required also at a step before DNA synthesis (Umar et al. 1996). Because of the high-affinity interaction between PCNA and MSH6 and MSH3, it had been anticipated that the latter requirement will involve MutS $\alpha$ or MutS $\beta$, respectively (Kleczkowska 2001; Shell et al. 2007b). However, deletion of the amino-terminal sequences of human MSH6 failed to fully abrogate MMR in vitro, which led to the suggestion that PCNA is required for interactions with members of the mismatch repairosome other than MutS $\alpha$ (Iyer et al. 2008; Pluciennik et al. 2009). Indeed, follow-up experiments suggested that PCNA is required to activate the latent endonuclease of MutL $\alpha$.

This key breakthrough was based on a large body of work that had originally set out to test the hypothesis of Claverys and Lacks (1986) that MMR in most organisms is directed by strand discontinuities. Evidence in support of this hypothesis came from in vivo studies in S. cerevisiae showing that the lagging strand was more efficiently repaired by MMR (Pavlov et al. 2003; Nick McElhinny et al. 2010) possibly due to the ready availability of DNA termini where MMR could initiate. The hypothesis could also be substantiated by in vitro studies using extracts of human cells and circular substrates carrying single mismatches. The mismatch was placed in a restriction enzyme recognition sequence such that the heteroduplex became refractory to cleavage by the given enzyme, but susceptible to cleavage upon strand-specific correction of the mismatch that restored the restriction site (Fig. 5). In these experiments, covalently closed heteroduplexes were seen to be largely refractory to repair, but introduction of a single nick within $\sim 1 \mathrm{~kb}$ of the mismatch brought about efficient repair that was directed predominantly to the nicked strand (Holmes et al. 1990; Thomas et al. 1991). Importantly, the restriction site could be restored when the nick was positioned $5^{\prime}$ or $3^{\prime}$ from the site, which implied that MMR in this system was bidirectional. This finding was initially not surprising, given that MMR in E. coli deployed several $5^{\prime} \rightarrow$ $3^{\prime}$ and $3^{\prime} \rightarrow 5^{\prime}$ exonucleases (see below). However, genetic experiments in yeast and later in higher organisms implicated only a single nuclease in MMR, exonuclease 1 (EXO1), that has an obligate $5^{\prime} \rightarrow 3^{\prime}$ polarity (for review, see Tran et al. 2004). Seen in the light of the Claverys and Lacks (1968) hypothesis, this result could explain postreplicative MMR in the lagging strand, where Okazaki fragment termini present EXO1 with ample loading sites, but not in the leading strand, where the only available terminus is the $3^{\prime}$ end of the primer strand.

Unexpectedly, when the human MMR system was reconstituted from MutS $\alpha$, MutL $\alpha$, EXO1, PCNA, RFC, and the single-strand-binding protein RPA, it was still capable of mismatch-provoked bidirectional excision (Genschel et al. 2002; Dzantiev et al. 2004), and when this system was supplemented with polymerase $\delta$, it performed both $5^{\prime}$-nick-directed MMR (Zhang et al. 2005) and bidirectional MMR (Constantin et al. 2005). Because $5^{\prime} \rightarrow$ $3^{\prime}$ excision solely required MutS $\alpha, \mathrm{EXO} 1$, and RPA, it was originally thought that EXO1 may also carry a cryptic $3^{\prime} \rightarrow 5^{\prime}$ activity that might be activated by PCNA, with which EXO1 interacts very strongly and which is required for $3^{\prime} \rightarrow 5^{\prime}$ excision (Dzantiev et al. 2004; Guo et al. 2004). But the explanation lay elsewhere: Close 
A
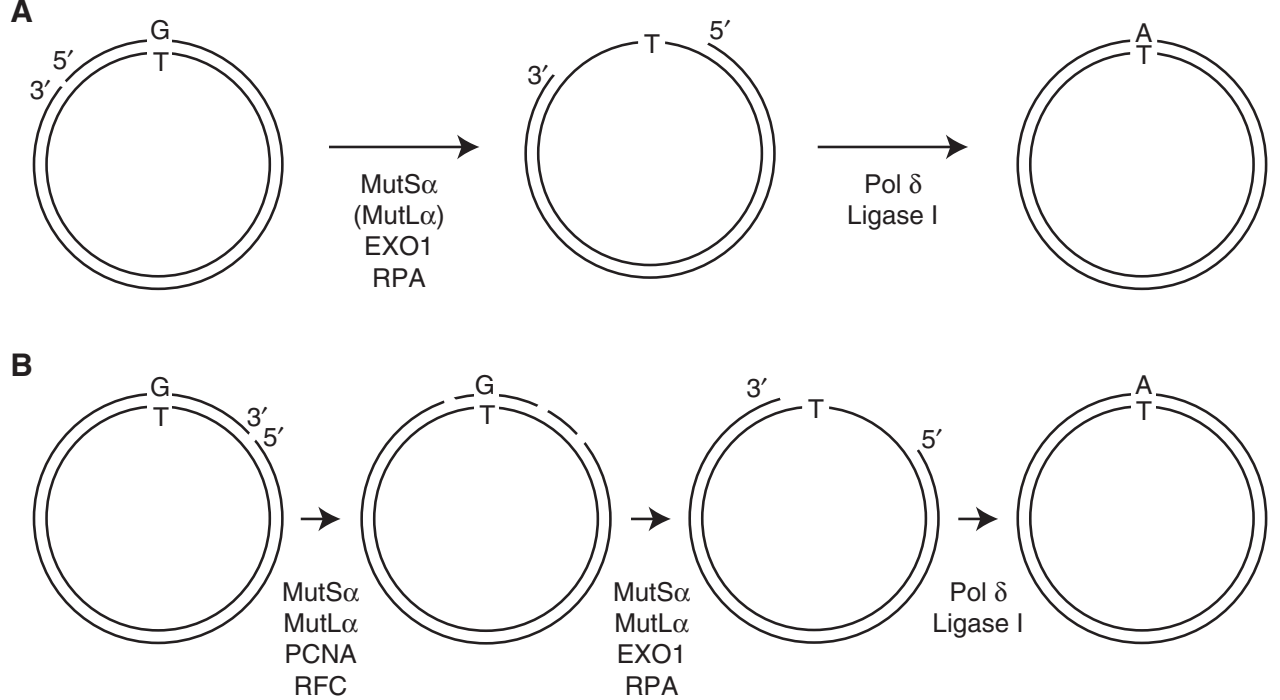

Figure 5. Schematic representation of the heteroduplex substrates used in in vitro MMR assays. The mismatch ( $\mathrm{G} / \mathrm{T}$, in this example) is positioned in a restriction enzyme recognition sequence and the plasmid is thus refractory to cleavage by this enzyme. Although covalently closed circular heteroduplexes remain largely refractory to restriction digestion, introduction of a single nick either $5^{\prime}(A)$, or $3^{\prime}(B)$ from the mispaired G results in $\mathrm{G} / \mathrm{T}$ to $\mathrm{A} / \mathrm{T}$ correction, as measured by the efficiency of restriction cleavage. In the human system, $5^{\prime} \rightarrow 3^{\prime}$ excision $A$ requires MutS $\alpha$, EXO1, and RPA. $3^{\prime} \rightarrow 5^{\prime}$ excision $B$ requires, in addition, MutL $\alpha$, PCNA, and RFC. In the latter system, the mismatch-activated MutS $\alpha / \operatorname{MutL} \alpha / \mathrm{PCNA}$ complex generates additional nicks in the prenicked strand that are used as EXO1 loading sites for $5^{\prime} \rightarrow 3^{\prime}$ excision of the error-containing strand.

analysis of the reconstituted system revealed that MutL $\alpha$ harbors cryptic endonuclease activity activated through interaction with $\mathrm{MutS} \alpha$, heteroduplex, and PCNA (Kadyrov et al. 2006, 2007). This activity was seen to introduce additional strand breaks into the $3^{\prime}$-nicked strand of the heteroduplex, particularly into the region between the nick and $\sim 150$ nucleotides past the mismatch. These nicks were then used as loading sites for EXO1 that was able to degrade the DNA in a $5^{\prime} \rightarrow 3^{\prime}$ direction between the MutL $\alpha$-generated breaks and the original $3^{\prime}$ nick. In the event that the degraded fragment included the mispaired nucleotide, EXO1 was no longer stimulated and the degradation process ceased. The single-stranded gap could then be filled in by polymerase $\delta$.

As discussed above, MutL $\alpha$ creates additional loading sites for EXO1; the two enzymes apparently work in concert in S. cerevisiae, because EXO1 was shown to interact with MLH1 via a highly conserved motif in the latter poly- peptide, and mutation of this site gave rise to a phenotype resembling an EXO1 hypomorph (Dherin et al. 2009). However, in the absence of EXO1, a limited amount of MMR could still be detected in vitro, and this reaction required the MutL $\alpha$ endonuclease and a DNA polymerase. The mechanism most likely involves a strand displacement reaction by the polymerase that deploys at MutL $\alpha$-generated nicks (Kadyrov et al. 2009). Although this reaction was not very efficient in the in vitro system, it might be more efficient in vivo: The mutator phenotype of cells lacking EXO1 is substantially weaker than that of cells deficient in MSHs or MLHs, and it had been argued that a subset of mismatches must be repaired by a mechanism that deploys a nuclease other than EXO1 or by a different MMR mechanism (Tran et al. 2004). This hypothesis has most recently found additional support in the finding that the contribution of EXO1 to leading strand MMR was very limited (Hombauer et al. 2011). 
J. Jiricny

The discovery of the MutL $\alpha$ endonuclease showed that MMR could also work in the "continuous" leading strand. But how could MutL $\alpha$ distinguish between the intact and the nicked strands and introduce new breaks selectively into the latter? This puzzle was answered in a seminal study showing that the endonuclease of MutL $\alpha$ is activated through association with PCNA (Pluciennik et al. 2010). As already mentioned, RFC loads PCNA at boundaries between double- and single-stranded DNA, such as at $3^{\prime}$ primer termini, but, importantly, it always loads it with the same (so-called proximal) side facing the DNA terminus (McNally et al. 2010). This implies that proteins interacting with RFC will bind to DNA in an orientation dictated by the PCNA clamp. Because MutS $\alpha$ and MutL $\alpha$ also enclose the DNA helix, the ternary complex with PCNA will have a fixed geometry and although able to slide along the DNA contour and rotate, it will not be able to flip round. Combined with the fact that the MutL $\alpha$ endonuclease is encoded only in the PMS2 subunit (Kadyrov et al. 2006) and that only one strand of the bound duplex has the correct orientation $\left(5^{\prime} \rightarrow\right.$ $3^{\prime}$ or $3^{\prime} \rightarrow 5^{\prime}$ ) for hydrolysis of the phosphodiester backbone, the enzyme will be able to cleave only a single strand of the duplex and, importantly, always the same one, irrespective of how far the ternary complex has diffused from its assembly point (for further discussion, see Peña-Diaz and Jiricny 2012).

How can this system operate in prokaryotes that express homodimeric MutL endonuclease, such as the prototypic S. pneumoniae or B. subtilis? The carboxy-terminal domain of MutL protein from the latter organism, which contains the endonuclease active site, could be crystallized, and the structure was modeled onto the crystal structure of $\beta$ from a related Grampositive bacterium Streptococcus pyrogenes. This work showed that the docking of one MutL subunit with $\beta$ would prevent the second MutL subunit from associating with the clamp (Pillon et al. 2010, 2011). Because endonuclease activity of MutL is dependent on its interaction with $\beta$, this would explain why only a single subunit of this homodimeric protein would be active as an endonuclease.

\section{MMR IN E. coli: THE EXCEPTION RATHER THAN THE RULE}

Despite the considerable evolutionary conservation among members of the MutL protein family, MutL orthologs of some Gram-negative bacteria do not have endonuclease activity; instead, they rely on the MutH protein, a cryptic endonuclease that is specifically activated by MutS/MutL. Paradoxically, E. coli, which has served as the paradigm for MMR for several decades, falls into this category. The E. coli MMR pathway will be discussed only briefly here, given the number of extensive reviews on this topic (Modrich and Lahue 1996; Jiricny 1998; Kunkel and Erie 2005a; Iyer et al. 2006; Jiricny 2006; Hsieh and Yamane 2008; Li 2008).

Genetic experiments performed in the 1960s identified several E. coli mutator strains, four of which were believed-and later confirmed-to have defects in MMR: mutS, mutL, mutH, and mut $U($ uvrD) (for a detailed treatise, see Chap. 12 in Friedberg et al. 2006). MutS and MutL were already discussed. MutH is a cryptic endonuclease that belongs to a protein family containing several restriction enzymes carrying a conserved PD-D/E(X)K motif (Kinch et al. 2005). Once activated, MutH can cleave GATC sequences (Lee et al. 2005) selectively in the nascent strand, which remains transiently unmethylated because deoxyadenine methylase (Dam) lags behind the replication fork by about $2 \mathrm{~min}$. Licensing of MutH involves interaction with mismatchand ATP-activated MutS and MutL. Directional loading of the $3^{\prime} \rightarrow 5^{\prime}$ UvrD (MutU) helicase at the site of the incision (Hall et al. 1998; Matson and Robertson 2006) leads to unwinding of the error-containing strand toward and past the mismatch. The displaced strand is degraded by the $5^{\prime} \rightarrow 3^{\prime}$ exonucleases ExoVII or RecJ if the MutH-induced nick was $5^{\prime}$ from the misincorporated nucleotide or by the $3^{\prime} \rightarrow 5^{\prime}$ exonucleases ExoI or ExoX if the nick was $3^{\prime}$ from the nucleotide. In this system, the MutL protein is believed to be required to mediate the interaction between the mismatch-activated MutS and the MutH endonuclease. Interestingly, MutH interacts with the carboxyl terminus of MLH1, the domain that houses the endonuclease in 
other MLHs, which makes it possible that the overall geometry of the strand incision complex is similar in all organisms. Indeed, E. coli MutS and MutL interact with $\beta$, like their homologs from other organisms (López de Saro et al. 2006). Interestingly, when the $\beta$-interaction site with MutL or the amino terminus of MutS was mutated, MMR was handicapped. However, disruption of a second $\beta$-interacting motif near the E. coli MutS carboxyl terminus had little effect, even though disruption of the homologous site in $\beta$ of $B$. subtilis abolished MMR (Simmons et al. 2008). Thus, despite considerable evolutionary conservation, there are significant differences even between bacterial systems. In this instance, the ability of the E. coli MMR system to make use of adenine methylation dispenses - at least partiallywith the need for an intimate link to the replication machinery.

\section{VISUALIZATION OF MMR IN VIVO}

MMR is a dynamic process and there can be little doubt that our understanding of it would be improved by being able to visualize it in living cells, as has been done in the case of other repair pathways (Dinant et al. 2007). In B. subtilis, GFP-labeled MutS and MutL variants were used to show that the proteins localized to foci induced by 2-aminopurine treatment, which generates mispairs in DNA. The formation of these foci was dependent on the ability of MutS to interact with $\beta$ (Simmons et al. 2008). In E. coli, a similar strategy was deployed to visualize nascent mutations, that is, mispairs that escaped repair after replication and that persisted until the following round of replication (Elez et al. 2010). Interestingly, the foci that persisted were those generated by MutL rather than MutS.

Foci of fluorescently labeled MSH6 and PMS1 were observed in S. cerevisiae (Hombauer et al. 2011). This work showed that the formation of MutS $\alpha$ foci was dependent on the ability of the MSH6 amino terminus to interact with PCNA and that this complex was an integral part of the so-called "replication factories" (Kitamura et al. 2006; see also Kleczkowska 2001).
Because expression of a fluorescently tagged amino terminus of MSH6 also gave rise to these foci, and because their number did not increase in cells with increased mutation rates, it was suggested that these foci were not arising at mismatches. In contrast, foci of MutL $\alpha$ appeared later, their number increased in mutator cells, and their formation was dependent on MutS $\alpha$. This seminal work has important implications for our understanding of MMR (see below).

Attempts to visualize MMR in human cells have been hampered by the lack of stable cell lines expressing physiologically relevant amounts of fluorescently labeled MMR proteins.

\section{MMR PROTEINS IN OTHER PATHWAYS OF DNA METABOLISM}

The involvement of MMR proteins in DNA recombination, both mitotic and meiotic, has been documented in a very large number of studies. Meiotic recombination largely involves MutL $\gamma$, the heterodimer of MLH1 and MLH3 (Lipkin et al. 2000, 2002; Nishant et al. 2008), that appears to function together with MSH4/ MSH5 (Snowden et al. 2004, 2008), a heterodimer that has no function in MMR. However, $\mathrm{PMS}^{-/-}$male mice are sterile, which implicates MutL $\alpha$ in a subset of these processes (see Chen et al. 2005, and references therein).

The roles of MMR proteins in homologous recombination and nonhomologous end joining of double-strand breaks have been comprehensively reviewed (Surtees et al. 2004; George and Alani 2012) and are not discussed here.

MMR proteins have also recently been implicated in DNA metabolic pathways other than correction of replication errors and recombination. MutS $\beta$ is required for triplet repeat expansion, the cause of several neurodegenerative diseases (for review, see McMurray 2008; Peña-Diaz and Jiricny 2012). The molecular mechanism is unknown at present but may involve interplay between recognition of stemloop structures arising at unstable triplet repeats and the processing of oxidative damage by the base excision repair system, namely, the 8-oxoguanine DNA glycosylase OGG1 (Kovtun et al. 2007). The involvement of MMR in oxidative 
J. Jiricny

damage processing has been documented earlier (Kim et al. 2003; Larson et al. 2003; Russo et al. 2004; Bai and Lu 2007) but is still ill understood. MSH6 has been reported to physically interact with MYH, the DNA glycosylase that removes adenines from mispairs with 8-oxoguanine ( $\mathrm{Gu}$ et al. 2002), and mutations in the interaction domain may be linked to cancer in humans (Bai et al. 2005, 2007), similarly to the inactivation of both genes in mouse models (Russo et al. 2009).

Oxidative damage was also reported to trigger MutS $\alpha$-dependent monoubiquitylation of PCNA (Zlatanou et al. 2011), a posttranslational modification that recruits translesion polymerases to sites of DNA damage (Friedberg et al. 2005). These data implicated MMR in error-prone DNA synthesis. It now appears that PCNA monoubiquitylation is generally induced when DNA damage (uracil, $O^{6}$-methylguanine) occurring outside of S-phase activates MMR, which generates long excision tracts that cannot be readily filled in by high-fidelity polymerases (Peña-Diaz et al. 2012). The latter findings provide a possible explanation for the involvement of MMR proteins in antibody maturation, where-counterintuitively-they are required for immunoglobulin mutagenesis, rather than for its prevention (Chahwan et al. 2011; PeñaDiaz and Jiricny 2012).

The propensity of MMR to generate persistent single-stranded gaps has been documented during the processing of $O^{6}$-methylguanine induced by $\mathrm{S}_{\mathrm{N}} 1$-type methylating agents. This modified base has no perfect base-pairing partner. Thus, incorporation of Tor C opposite $O^{6}$ methylguanine will activate MMR. However, repair synthesis will regenerate the mispair and this will trigger iterative rounds of MMR (York and Modrich 2006). After several unsuccessful attempts, the repair polymerase appears to abandon its efforts and leaves a persistent single-stranded gap opposite the modified nucleotide (Mojas et al. 2007). In vivo, these gaps are believed to persist until the next round of replication, when they will give rise to a doublestrand break at the replication fork, an $\mathrm{S} / \mathrm{G}_{2}$ cell cycle arrest, and cell death. This MMR-dependent mechanism of cell killing is likely to explain the more than 100-fold resistance of MMR-deficient cells to $S_{\mathrm{N}} 1$-type methylating agents (for review, see Bignami et al. 2000; Stojic et al. 2004; Hsieh and Yamane 2008). MMR proteins were also reported to signal the presence of methylation damage directly through the ATR kinase (Yoshioka et al. 2006) and were also shown to physically interact with members of the ATRCHK1 checkpoint pathway (Liu et al. 2010b), but the significance of these interactions is currently unclear.

\section{MMR INTERACTOME}

Ample experimental evidence documents the involvement of MMR proteins in different pathways of DNA metabolism. In an attempt to throw some light on their function(s) in these processes, considerable effort has been devoted to the characterization of the MMR interactome. In pioneering efforts, MSH2, MSH6, and MLH1 were reported to associate with BRCA1 (Wang et al. 2000), MSH2 was seen to localize to recombination foci in $S$. cerevisiae (Evans et al. 2000), and MMR proteins were reported to be recruited to sites of laser-induced DNA damage (Hong et al. 2008). Taken together, these results provided a biochemical basis for the involvement of MMR in recombination and double-strand break repair, which had been documented in genetic experiments many years earlier (see Chap. 12 in Friedberg et al. 2006).

Using a proteomic approach, the interactomes of human MLH1, PMS2, and PMS1 were characterized (Cannavo et al. 2007). This study identified an interaction between MutL $\alpha$ and FANCJ, a protein that participates in the Fanconi anaemia (FA) pathway of interstrand cross-link repair and that was first isolated as a BRCA1-interacting protein (BRIP1, also known as BACH1) (Cantor et al. 2001). This interaction was independently confirmed (Peng et al. 2007) but remains without a clear function. The MLH1 interactome contained a previously uncharacterized protein, KIAA1018, that was shown to encode a novel endonuclease that preferentially cleaves $5^{\prime}$ flap structures. The protein has been named FANCD2-associated nuclease 1 
(FAN1) because of its role in interstrand crosslink repair and its association with FANCD2, a key member of the FA pathway (Kratz et al. 2010; Liu et al. 2010a; MacKay et al. 2010; Smogorzewska et al. 2010; Yoshikiyo et al. 2010). FAN1 was recently-and unexpectedly-linked to nephritis in humans (Zhou et al. 2012).

$\mathrm{MSH}$ interactomes have not been studied by the same methods as those of MLHs, possibly because their key interaction partners were identified by conventional methods. Alignment of the amino acid sequences of MSHs shows a considerable degree of conservation around the mismatch and DNA-bindings sites as well as in the ATP-binding/dimerization domains. However, MSH3 and MSH6 carry long amino-terminal extensions that contain PCNA interacting peptide (PIP) motifs at their extreme amino termini (Fig. 6A) but that are otherwise conserved in neither length nor sequence. Analysis of the $S$. cerevisiae amino terminus by partial proteolysis and small-angle X-ray scattering (SAXS) suggested that the region is largely unstructured and is required primarily for interaction with PCNA, not solely via the PIP motif, but also through a second region encompassing amino acids 123-251 (Shell et al. 2007b). In the human protein, where the amino-terminal extension is longer, amino-terminal 350 amino acids were cleaved off by trypsin as a single domain (Iaccarino 1998). In SAXS analysis, the amino-terminal domain extended the length of the MSH6 subunit, as in the yeast protein, and the PCNA ring was stacked onto this domain, forming numerous contacts (Fig. 6B). This would explain why deletion of the PIP motif failed to fully inactivate MMR in vitro (Kleczkowska 2001; Iyer et al. 2008) and in vivo (Shell et al. 2007b). However, the human amino terminus of MSH6 is likely to be more structured because it contains several motifs that are absent in the yeast ortholog. One of these is the PWWP motif that is found in several chromatin-associated proteins (Laguri et al. 2008). The human MSH6 amino-terminal domain also interacts with chromatin assembly factor CAF-1 (Schöpf et al. 2012). It was postulated that this function might inhibit nucleosome deposition on newly synthesized DNA to extend the time window available for MMR (Kadyrova et al. 2011; Schöpf et al. 2012), given that nucleosomes assemble behind the replication fork within seconds (Lucchini et al. 2001) and that their presence would block the MutS $\alpha /$ MutL $\alpha$ complex from translocating along the DNA contour ( $\mathrm{Li}$ et al. 2009), even though this sliding clamp might be able to remodel and/or displace some nucleosomes (Javaid et al. 2009) or even "sidestep" them (Gorman et al. 2010).

\section{CLINICAL RELEVANCE OF MMR}

MMR malfunction is linked to Lynch syndrome (also known as hereditary nonpolyposis colon cancer [HNPCC]), one of the most common genetic predispositions to cancer of the colon, endometrium, ovary, and other tissues (for recent review, see Lynch et al. 2009). The most common mutations affect $\mathrm{MSH} 2$ and $\mathrm{MLH1}$ genes that effectively inactivate MMR. Mutations in MSH6 and PMS2 are rare and less penetrant. Lynch syndrome accounts for $\sim 3 \%-4 \%$ of all colorectal cancer cases, but an additional $\sim 10 \%$ of colon tumors are MMR deficient due to epigenetic silencing of the $M L H 1$ gene by cytosine methylation (Peltomäki 2012). The MMR defect is readily detected as microsatellite instability (MSI), caused by the lack of repair of small IDLs in repeated sequence elements (microsatellites) that are present in the human genome in very large numbers. MSI analysis represents a widely used biomarker of MMR-deficient tumors. Of the numerous MMR gene mutations that have been identified to date (http://www.insight-group.org), many are missense, which makes it difficult to predict whether they deleteriously affect MMR. The genotype/phenotype correlation is of great importance to gastroenterologists and genetic counselors, especially in cohorts where the segregation of the mutation with the disease is difficult to establish (small family size, unavailability of family history, of DNA samples, etc.). To overcome this problem, several groups have established functional tests that help to define whether a given mutation is linked to an MMR defect (Trojan et al. 2002; Raevaara et al. 2005; Plotz et al. 2006; Erdeniz et al. 2007; Wanat et al. 
J. Jiricny
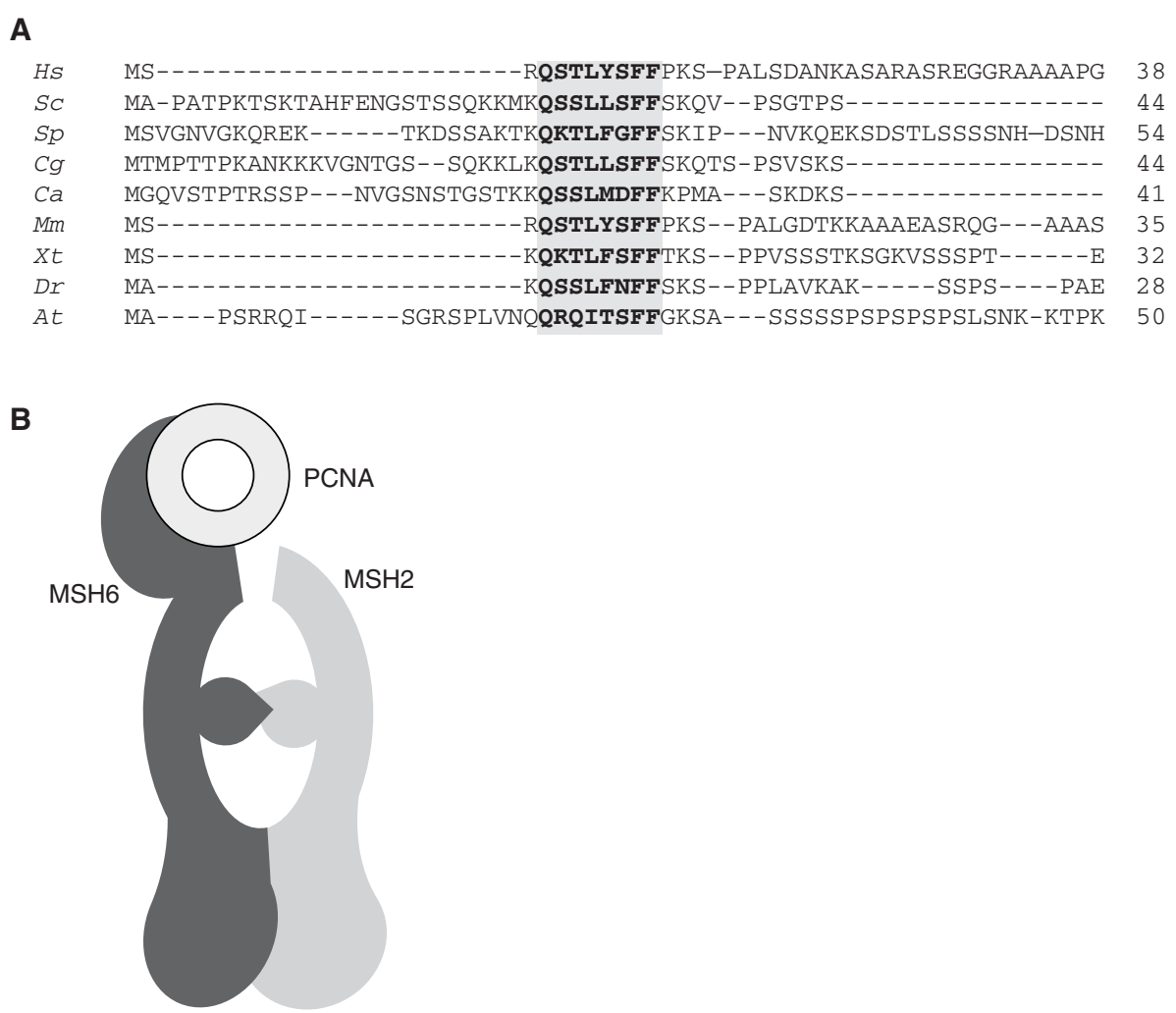

Figure 6. MSH6-PCNA interaction. (A) Evolutionary conservation of the eukaryotic PIP motif (bold on grey background). Hs, Homo sapiens; Sc, Saccharomyces cerevisiae; Sp, Schizosaccharomyces pombe; Cg, Cricetulus griseus; Ca, Candida albicans; Mm, Mus musculus; Xt, Xenopus tropicalis; Dr, Danio rerio; At, Arabidopsis thaliana. (B) Schematic representation of human MutS $\alpha$ in complex with PCNA derived from SAXS analysis (Iyer et al. 2008). Although the interaction among these proteins has been believed to be mediated by the PIP motif, PCNA is contacted by many residues of the amino-terminal domain of MSH6, as predicted from experiments with the yeast factor (Shell et al. 2007b). The PIP motif is thus possibly only a docking motif that brings the two polypeptides into close proximity, such that they can interact more intimately. This might help to explain why mutation of PIP motifs of several PCNA interacting proteins often fails to abolish their function.

2007; Martinez and Kolodner 2010). Most of these tests are complex and require specialized knowledge, but attempts are underway to bring them within reach of routine diagnostic laboratories (Drost et al. 2010, 2012).

MMR also has a key role in the control of a curious process that has stimulated a great deal of discussion and controversy: targeted gene alteration (Engstrom et al. 2009), best described as oligonucleotide-directed mutagenesis in vivo. This process is currently functioning in systems where positive selection for mutants is possible, for example, in S. cerevisiae (Kow et al. 2007; Rodriguez et al. 2012) and mouse (Dekker et al.
2011), but it is hoped that once its limitations are understood and overcome, it may find use in the therapy of genetic diseases by correcting inherited mutations (Papaioannou et al. 2012).

\section{CONCLUDING REMARKS}

The study of MMR has made substantial progress in recent years, largely thanks to emerging technologies that have provided novel—or confirmed existing - insights into the mechanism of this complex pathway of DNA metabolism. On the basis of these findings, a molecular 

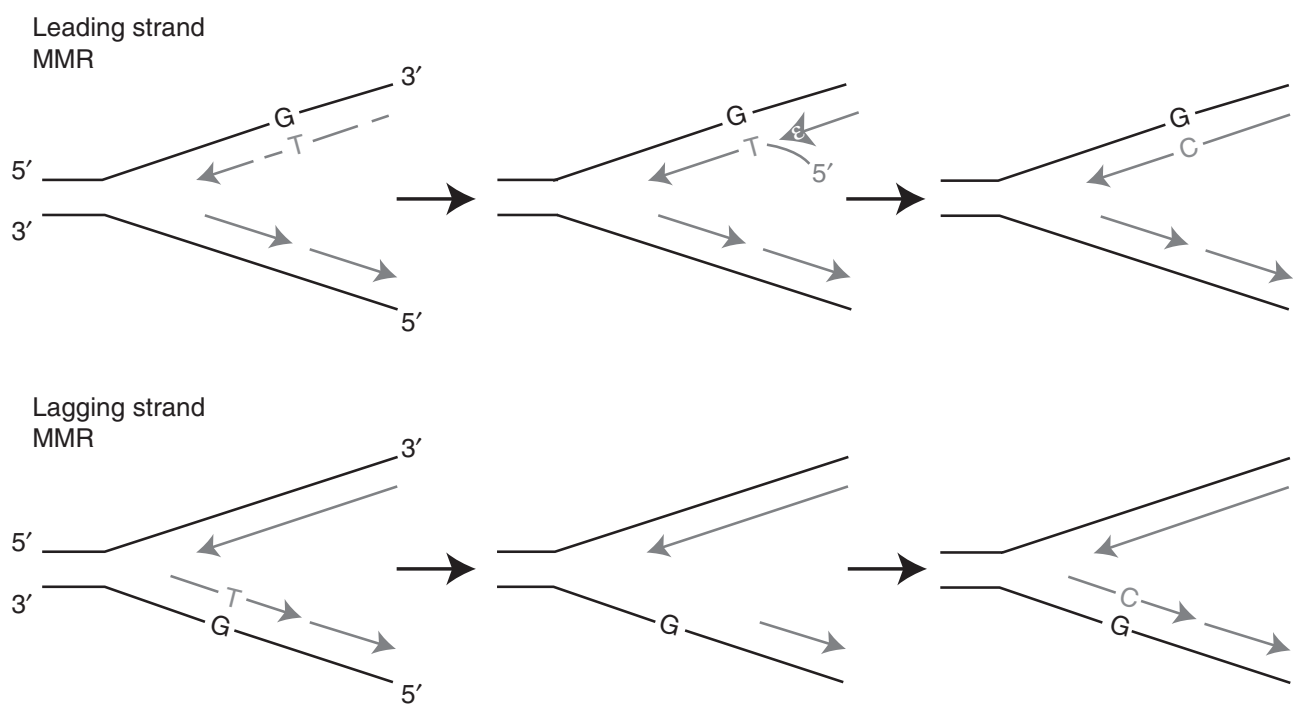

Figure 7. Alternative schemes of MMR in the leading and lagging strands. A mismatch in the leading strand will require the mismatch-activated MutS $\alpha / \operatorname{MutL} \alpha / \mathrm{PCNA}$ complex to introduce breaks into the nascent strand (left). Once introduced, these breaks can be used as loading sites for EXO1 or, alternatively, as sites of strand displacement by a polymerase loaded at a $3^{\prime}$ terminus upstream of the misincorporated nucleotide (middle). Strand displacement would not require EXO1 but would be dependent on PCNA and the flap-endonuclease FEN1. Mismatch repair in the lagging strand may not absolutely require the MutL $\alpha$ endonuclease, due to the availability of free $5^{\prime}$ termini. MMR in the newest Okazaki fragment will absolutely require EXO1, given that there is no upstream $3^{\prime}$ terminus at which strand displacement might initiate. The repair process might involve the resynthesis of the entire Okazaki fragment (middle).

model for MMR is beginning to emerge (Fig. 7) that satisfies the criteria for successful repair.

Despite these advances, four key questions remain: (1) Where does the MSH/MLH complex assemble? At the mismatch? At the stranddiscrimination signal? (2) If the complex does assemble at the mismatch and translocates, does it diffuse randomly in either direction, or is the direction of its travel dictated by the orientation of its initial loading on the heteroduplex? (3) How is the exonuclease directed to degrade the fragment containing the misincorporated nucleotide toward the mismatch rather than away from it? (4) Is there another exonuclease involved in MMR, and, if so, which? It is hoped that future work will provide answers to these questions as well as help to elucidate the molecular role(s) of MMR proteins in DNA metabolic processes ranging from recombination through triplet repeat expansion and antibody diversification to the processing of interstrand crosslinks.

\section{ACKNOWLEDGMENTS}

I am grateful to my wife and to the members of my laboratory for their support and interminable patience. I acknowledge Joyce Lebbink for her kind help with Figure 2. I apologize to those whose work is not mentioned here; in the past 6 years, more than 600 publications on "mismatch repair" have appeared in the literature and it was impossible to include them all in this article. The financial support of the Seventh Framework Program of the European Community (grant $223545 \mathrm{~mm} 2 \mathrm{~m}$ ), the Swiss National Science Foundation (grant 310030B-133123), and the European Research Council (advanced grant 294537 "MIRIAM") are gratefully acknowledged.

\section{REFERENCES}

Acharya S, Foster PL, Brooks P, Fishel R. 2003. The coordinated functions of the E. coli MutS and MutL proteins in mismatch repair. Mol Cell 12: 233-246. 
J. Jiricny

Alani E, Sokolsky T, Studamire B, Miret JJ, Lahue RS. 1997. Genetic and biochemical analysis of Msh2p-Msh6p: Role of ATP hydrolysis and Msh2p-Msh6p subunit interactions in mismatch base pair recognition. Mol Cell Bio 17: 2436-2447.

Antony E, Hingorani MM. 2003. Mismatch recognitioncoupled stabilization of Msh2-Msh6 in an ATP-bound state at the initiation of DNA repair. Biochemistry 42 $7682-7693$.

Arana ME, Kunkel TA. 2010. Mutator phenotypes due to DNA replication infidelity. Semin Cancer Biol 20: $304-$ 311.

Bai H, Lu A-L. 2007. Physical and functional interactions between Escherichia coli MutY glycosylase and mismatch repair protein MutS. J Bacteriol 189: 902-910.

Bai H, Jones S, Guan X, Wilson TM, Sampson JR, Cheadle JP, Lu A-L. 2005. Functional characterization of two human MutY homolog (hMYH) missense mutations (R227W and V232F) that lie within the putative hMSH6 binding domain and are associated with hMYH polyposis. Nucleic Acids Res 33: $597-$ 604.

Bai H, Grist S, Gardner J, Suthers G, Wilson TM, Lu A-L. 2007. Functional characterization of human MutY homolog (hMYH) missense mutation (R231L) that is linked with hMYH-associated polyposis. Cancer Lett 250: 74-81.

Bignami M, O'Driscoll M, Aquilina G, Karran P. 2000. Unmasking a killer: DNA $O^{6}$-methylguanine and the cytotoxicity of methylating agents. Mutat Res 462: 7182.

Bjornson KP, Modrich P. 2003. Differential and simultaneous adenosine di- and triphosphate binding by MutS. $J$ Biol Chem 278: 18557-18562.

Blackwell LJ, Bjornson KP, Modrich P. 1998. DNA-dependent activation of the hMutS $\alpha$ ATPase. J Biol Chem 273: 32049-32054.

Blackwell LJ, Wang S, Modrich P. 2001. DNA chain length dependence of formation and dynamics of hMutS $\alpha \cdot \mathrm{hMutL} \alpha \cdot$ heteroduplex complexes. J Biol Chem 276: 33233-33240.

Cannavo E, Marra G, Sabates-Bellver J, Menigatti M, Lipkin SM, Fischer F, Cejka P, Jiricny J. 2005. Expression of the MutL homologue hMLH3 in human cells and its role in DNA mismatch repair. Cancer Res 65: 10759-10766.

Cannavo E, Gerrits B, Marra G, Schlapbach R, Jiricny J. 2007. Characterization of the interactome of the human MutL homologues MLH1, PMS1, and PMS2.J Biol Chem 282: 2976-2986.

Cantor SB, Bell DW, Ganesan S, Kass EM, Drapkin R, Grossman S, Wahrer DC, Sgroi DC, Lane WS, Haber DA, et al. 2001. BACH1, a novel helicase-like protein, interacts directly with BRCA1 and contributes to its DNA repair function. Cell 105: 149-160.

Chahwan R, Edelmann W, Scharff MD, Roa S. 2011. Mismatch-mediated error prone repair at the immunoglobulin genes. Biomed Pharmacother 65: 529-536.

Chen PC, Dudley S, Hagen W, Dizon D, Paxton L, Reichow D, Yoon SR, Yang K, Arnheim N, Liskay RM, et al. 2005. Contributions by MutL homologues Mlh3 and Pms2 to DNA mismatch repair and tumor suppression in the mouse. Cancer Research 65: 8662-8670.
Chi NW, Kolodner RD. 1994. The effect of DNA mismatches on the ATPase activity of MSH1, a protein in yeast mitochondria that recognizes DNA mismatches. J Biol Chem 269: 29993-29997.

Cho WK, Jeong C, Kim D, Chang M, Song KM, Hanne J, Ban C, Fishel R, Lee JB. 2012. ATP alters the diffusion mechanics of MutS on mismatched DNA. Structure 20: 1264-1274.

Claverys JP, Lacks SA. 1986. Heteroduplex deoxyribonucleic acid base mismatch repair in bacteria. Microbiol Rev 50: $133-165$.

Constantin N, Dzantiev L, Kadyrov FA, Modrich P. 2005. Human mismatch repair: Reconstitution of a nick-directed bidirectional reaction. J Biol Chem 280: 3975239761.

Dalrymple BP, Kongsuwan K, Wijffels G, Dixon NE, Jennings PA. 2001. A universal protein-protein interaction motif in the eubacterial DNA replication and repair systems. Proc Natl Acad Sci 98: 11627-11632.

Dekker M, de Vries S, Aarts M, Dekker R, Brouwers C, Wiebenga $\mathrm{O}$, de Wind N, Cantelli E, Tonelli R, Riele Te H. 2011. Transient suppression of MLH1 allows effective single-nucleotide substitution by single-stranded DNA oligonucleotides. Mutat Res 715: 52-60.

de Vries SS, Baart EB, Dekker M, Siezen A, de Rooij DG, de Boer P, Riele te H. 1999. Mouse MutS-like protein Msh5 is required for proper chromosome synapsis in male and female meiosis. Genes Dev 13: 523-531.

Dherin C, Gueneau E, Francin M, Nunez M, Miron S, Liberti SE, Rasmussen LJ, Zinn-Justin S, Gilquin B, Charbonnier J-B, et al. 2009. Characterization of a highly conserved binding site of Mlh1 required for exonuclease I-dependent mismatch repair. Mol Cell Biol 29: 907-918.

Dinant C, de Jager M, Essers J, van Cappellen WA, Kanaar R, Houtsmuller AB, Vermeulen W. 2007. Activation of multiple DNA repair pathways by sub-nuclear damage induction methods. J Cell Sci 120: 2731-2740.

Dowen JM, Putnam CD, Kolodner RD. 2010. Functional studies and homology modeling of Msh2-Msh3 predict that mispair recognition involves DNA bending and strand separation. Mol Cell Biol 30: 3321-3328.

Drost M, Zonneveld JBM, van Dijk L, Morreau H, Tops CM, Vasen HFA, Wijnen JT, de Wind N. 2010. A cell-free assay for the functional analysis of variants of the mismatch repair protein MLH1. Hum Mutat 31: 247-253.

Drost M, Zonneveld JBM, van Hees S, Rasmussen LJ, Hofstra RMW, de Wind N. 2012. A rapid and cell-free assay to test the activity of lynch syndrome-associated MSH2 and MSH6 missense variants. Hum Mutat 33: $488-494$.

Dufner P, Marra G, Räschle M, Jiricny J. 2000. Mismatch recognition and DNA-dependent stimulation of the ATPase activity of hMutS $\alpha$ is abolished by a single mutation in the hMSH6 subunit. J Biol Chem 275: 3655036555.

Dzantiev L, Constantin N, Genschel J, Iyer RR, Burgers PM, Modrich P. 2004. A defined human system that supports bidirectional mismatch-provoked excision. Mol Cell 15: $31-41$.

Elez M, Murray AW, Bi L-J, Zhang XE, Matic I, Radman M. 2010. Seeing mutations in living cells. Curr Biol 20: $1432-1437$. 
Engstrom JU, Suzuki T, Kmiec EB. 2009. Regulation of targeted gene repair by intrinsic cellular processes. Bioessays 31: $159-168$.

Erdeniz N, Nguyen M, Deschênes SM, Liskay RM. 2007. Mutations affecting a putative MutL $\alpha$ endonuclease motif impact multiple mismatch repair functions. DNA Repair 6: $1463-1470$.

Evans E, Sugawara N, Haber JE, Alani E. 2000. The Saccharomyces cerevisiae Msh2 mismatch repair protein localizes to recombination intermediates in vivo. Mol Cell 5: 789-799.

Flores-Rozas H, Kolodner RD. 1998. The Saccharomyces cerevisiae MLH3 gene functions in MSH3-dependent suppression of frameshift mutations. Proc Natl Acad Sci 95: 12404-12409.

Flores-Rozas H, Clark D, Kolodner RD. 2000. Proliferating cell nuclear antigen and Msh2p-Msh6p interact to form an active mispair recognition complex. Nat Genet 26: 375-378.

Friedberg EC, Walker GC, Siede W. 1995. DNA repair and mutagenesis. ASM Press, Washington, DC.

Friedberg EC, Lehmann AR, Fuchs RPP. 2005. Trading places: How do DNA polymerases switch during translesion DNA synthesis? Mol Cell 18: 499-505.

Friedberg EC, Walker GC, Siede W, Wood RD, Schultz RA, Ellenberger T. 2006. DNA repair and mutagenesis, 2 nd ed. ASM Press, Washington, DC.

Fukui K, Nakagawa N, Kitamura Y, Nishida Y, Masui R, Kuramitsu S. 2008. Crystal structure of MutS2 endonuclease domain and the mechanism of homologous recombination suppression. J Biol Chem 283: 3341733427.

Genschel J, Bazemore LR, Modrich P. 2002. Human exonuclease I is required for $5^{\prime}$ and $3^{\prime}$ mismatch repair. J Biol Chem 277: 13302-13311.

George CM, Alani E. 2012. Multiple cellular mechanisms prevent chromosomal rearrangements involving repetitive DNA. Crit Rev Biochem Molec Biol 47: 297-313.

Gorman J, Chowdhury A, Surtees JA, Shimada J, Reichman DR, Alani E, Greene EC. 2007. Dynamic basis for one-dimensional DNA scanning by the mismatch repair complex Msh2-Msh6. Mol Cell 28: 359-370.

Gorman J, Plys AJ, Visnapuu M-L, Alani E, Greene EC. 2010. Visualizing one-dimensional diffusion of eukaryotic DNA repair factors along a chromatin lattice. Nat Struct Mol Biol 17: 932-938.

Grilley M, Welsh KM, Su SS, Modrich P. 1989. Isolation and characterization of the Escherichia coli mutL gene product. J Biol Chem 264: 1000-1004.

Gu Y, Parker A, Wilson TM, Bai H, Chang D-Y, Lu A-L. 2002. Human MutY homolog, a DNA glycosylase involved in base excision repair, physically and functionally interacts with mismatch repair proteins human MutS homolog 2 / human MutS homolog 6. J Biol Chem 277: 11135-11142.

Guarné A. 2012. The functions of MutL in mismatch repair: The power of multitasking. Prog Mol Biol Transl Sci 110: 41-70.

Guo S, Presnell SR, Yuan F, Zhang Y, Gu L, Li G-M. 2004. Differential requirement for proliferating cell nuclear antigen in $5^{\prime}$ and $3^{\prime}$ nick-directed excision in human mismatch repair. J Biol Chem 279: 16912-16917.
Gupta S, Gellert M, Yang W. 2012. Mechanism of mismatch recognition revealed by human MutS $\beta$ bound to unpaired DNA loops. Nat Struct Mol Biol 19: 72-78.

Hall MC, Jordan JR, Matson SW. 1998. Evidence for a physical interaction between the Escherichia coli methyldirected mismatch repair proteins MutL and UvrD. EMBO J 17: 1535-1541.

Harfe BD, Minesinger BK, Jinks-Robertson S. 2000. Discrete in vivo roles for the MutL homologs Mlh2p and Mlh3p in the removal of frameshift intermediates in budding yeast. Curr Biol 10: 145-148.

Hargreaves VV, Shell SS, Mazur DJ, Hess MT, Kolodner RD. 2010. Interaction between the Msh2 and Msh6 nucleotide-binding sites in the Saccharomyces cerevisiae Msh2Msh6 complex. J Biol Chem 285: 9301-9310.

Harrington JM, Kolodner RD. 2007. Saccharomyces cerevisiae Msh2-Msh3 acts in repair of base-base mispairs. Mol Cell Biol 27: 6546-6554.

Heinen CD, Cyr JL, Cook C, Punja N, Sakato M, Forties RA, Lopez JM, Hingorani MM, Fishel R. 2011. Human MSH2 (hMSH2) protein controls ATP processing by hMSH2hMSH6. J Biol Chem 286: 40287-40295.

Hewish M, Lord CJ, Martin SA, Cunningham D, Ashworth A. 2010. Mismatch repair deficient colorectal cancer in the era of personalized treatment. Nat Rev Clin Oncol 7: 197-208.

Holmes J, Clark S, Modrich P. 1990. Strand-specific mismatch correction in nuclear extracts of human and Drosophila melanogaster cell lines. Proc Natl Acad Sci 87: 5837-5841.

Hombauer H, Campbell CS, Smith CE, Desai A, Kolodner RD. 2011. Visualization of eukaryotic DNA mismatch repair reveals distinct recognition and repair intermediates. Cell 147: 1040-1053.

Hong Z, Jiang J, Hashiguchi K, Hoshi M, Lan L, Yasui A. 2008. Recruitment of mismatch repair proteins to the site of DNA damage in human cells. J Cell Sci 121: 31463154.

Hsieh P, Yamane K. 2008. DNA mismatch repair: molecular mechanism, cancer, and ageing. Mech Ageing Dev 129: 391-407.

Huang S-YN, Crothers DM. 2008. The role of nucleotide cofactor binding in cooperativity and specificity of MutS recognition. J Molec Biol 384: 31-47.

Iaccarino I. 1998. hMSH2 and hMSH6 play distinct roles in mismatch binding and contribute differently to the ATPase activity of hMutS $\alpha$. EMBO J 17: 2677-2686.

Iyer RR, Pluciennik A, Burdett V, Modrich PL. 2006. DNA mismatch repair: Functions and mechanisms. Chem Rev 106: $302-323$.

Iyer RR, Pohlhaus TJ, Chen S, Hura GL, Dzantiev L, Beese LS, Modrich P. 2008. The MutS $\alpha$-proliferating cell nuclear antigen interaction in human DNA mismatch repair. J Biol Chem 283: 13310-13319.

Iyer RR, Pluciennik A, Genschel J, Tsai MS, Beese LS, Modrich P. 2010. MutL $\alpha$ and proliferating cell nuclear antigen share binding sites on MutS $\beta$. J Biol Chem 285: 11730-11739.

Javaid S, Manohar M, Punja N, Mooney A, Ottesen JJ, Poirier MG, Fishel R. 2009. Nucleosome remodeling by hMSH2-hMSH6. Mol Cell 36: 1086-1094. 
J. Jiricny

Jeong C, Cho WK, Song KM, Cook C, Yoon TY, Ban C, Fishel R, Lee JB. 2011. MutS switches between two fundamentally distinct clamps during mismatch repair. Nat Struct Mol Biol 18: 379-385.

Jiricny J. 1998. Replication errors: Cha(lle)nging the genome. EMBO J 17: 6427-6436.

Jiricny J. 2006. The multifaceted mismatch-repair system. Nat Rev Mol Cell Biol 7: 335-346.

Jiricny J, Hughes M, Corman N, Rudkin BB. 1988a. A human 200-kDa protein binds selectively to DNA fragments containing G.T mismatches. Proc Natl Acad Sci 85: 8860-8864.

Jiricny J, Su SS, Wood SG, Modrich P. 1988b. Mismatchcontaining oligonucleotide duplexes bound by the E. coli MutS-encoded protein. Nucleic Acids Res 16: 7843-7853.

Junop MS, Obmolova G, Rausch K, Hsieh P, Yang W. 2001. Composite active site of an ABC ATPase: MutS uses ATP to verify mismatch recognition and authorize DNA repair. Mol Cell 7: 1-12

Kadyrov FA, Dzantiev L, Constantin N, Modrich P. 2006 Endonucleolytic function of MutL $\alpha$ in human mismatch repair. Cell 126: 297-308.

Kadyrov FA, Holmes SF, Arana ME, Lukianova OA, O'Donnell M, Kunkel TA, Modrich P. 2007. Saccharomyces cerevisiae MutL $\alpha$ is a mismatch repair endonuclease. J Biol Chem 282: 37181-37190.

Kadyrov FA, Genschel J, Fang Y, Penland E, Edelmann W, Modrich P. 2009. A possible mechanism for exonuclease 1-independent eukaryotic mismatch repair. Proc Natl Acad Sci 106: 8495-8500.

Kadyrova LY, Blanko ER, Kadyrov FA. 2011. CAF-I-dependent control of degradation of the discontinuous strands during mismatch repair. Proc Natl Acad Sci 108: $2753-$ 2758.

Kim M, Huang T, Miller JH. 2003. Competition between MutY and mismatch repair at A x C mispairs in vivo. $J$ Bacteriol 185: 4626-4629.

Kinch LN, Ginalski K, Rychlewski L, Grishin NV. 2005. Identification of novel restriction endonuclease-like fold families among hypothetical proteins. Nucleic Acids Res 33: 3598-3605.

Kitamura E, Blow JJ, Tanaka TU. 2006. Live-cell imaging reveals replication of individual replicons in eukaryotic replication factories. Cell 125: 1297-1308.

Kleczkowska HE. 2001. hMSH3 and hMSH6 interact with PCNA and colocalize with it to replication foci. Genes Dev 15: 724-736.

Kneitz B, Cohen PE, Avdievich E, Zhu L, Kane MF, Hou H, Kolodner RD, Kucherlapati R, Pollard JW, Edelmann W. 2000. MutS homolog 4 localization to meiotic chromosomes is required for chromosome pairing during meiosis in male and female mice. Genes Dev 14: 1085-1097.

Kovtun IV, Liu Y, Bjoras M, Klungland A, Wilson SH, McMurray CT. 2007. OGG1 initiates age-dependent CAG trinucleotide expansion in somatic cells. Nature 447: 447-452.

Kow YW, Bao G, Reeves JW, Jinks-Robertson S, Crouse GF. 2007. Oligonucleotide transformation of yeast reveals mismatch repair complexes to be differentially active on DNA replication strands. Proc Natl Acad Sci 104: $11352-11357$.
Kratz K, Schöpf B, Kaden S, Sendoel A, Eberhard R, Lademann C, Cannavo E, Sartori AA, Hengartner MO, Jiricny J. 2010. Deficiency of FANCD2-associated nuclease KIAA1018/FAN1 sensitizes cells to interstrand crosslinking agents. Cell 142: 77-88.

Kunkel TA, Erie DA. 2005. DNA mismatch repair. Annu Rev Biochem 74: 681-710.

Laguri C, Duband-Goulet I, Friedrich N, Axt M, Belin P, Callebaut I, Gilquin B, Zinn-Justin S, Couprie J. 2008. Human mismatch repair protein MSH6 contains a PWWP domain that targets double stranded DNA. Biochemistry 47: 6199-6207.

Lamers MH, Perrakis A, Enzlin JH, Winterwerp HH, de Wind N, Sixma TK. 2000. The crystal structure of DNA mismatch repair protein MutS binding to a $\mathrm{G} x \mathrm{~T}$ mismatch. Nature 407: 711-717.

Lamers MH, Winterwerp HHK, Sixma TK. 2003. The alternating ATPase domains of MutS control DNA mismatch repair. EMBO J 22: 746-756.

Lamers MH, Georgijevic D, Lebbink JH, Winterwerp HHK, Agianian B, de Wind N, Sixma TK. 2004. ATP increases the affinity between MutS ATPase domains. Implications for ATP hydrolysis and conformational changes. J Biol Chem 279: 43879-43885.

Larson ED, Iams K, Drummond JT. 2003. Strand-specific processing of 8-oxoguanine by the human mismatch repair pathway: Inefficient removal of 8-oxoguanine paired with adenine or cytosine. DNA Repair 2: 1199-1210.

Lee SD, Alani E. 2006. Analysis of interactions between mismatch repair initiation factors and the replication processivity factor PCNA. J Molec Biol 355: 175-184.

Lee JY, Chang J, Joseph N, Ghirlando R, Rao DN, Yang W. 2005. MutH complexed with hemi- and unmethylated DNAs: Coupling base recognition and DNA cleavage. Mol Cell 20: 155-166.

Lee SD, Surtees JA, Alani E. 2007. Saccharomyces cerevisiae MSH2-MSH3 and MSH2-MSH6 complexes display distinct requirements for DNA binding domain I in mismatch recognition. J Molec Biol 366: 53-66.

Li GM. 2008. Mechanisms and functions of DNA mismatch repair. Cell Res 18: 85-98.

Li F, Tian L, Gu L, Li GM. 2009. Evidence that nucleosomes inhibit mismatch repair in eukaryotic cells. J Biol Chem 284: 33056-33061.

Lipkin SM, Wang V, Jacoby R, Banerjee-Basu S, Baxevanis AD, Lynch HT, Elliott RM, Collins FS. 2000. MLH3: A DNA mismatch repair gene associated with mammalian microsatellite instability. Nat Genet 24: $27-$ 35.

Lipkin SM, Moens PB, Wang V, Lenzi M, Shanmugarajah D, Gilgeous A, Thomas J, Cheng J, Touchman JW, Green ED, et al. 2002. Meiotic arrest and aneuploidy in MLH3-deficient mice. Nat Genet 31: 385-390.

Liu T, Ghosal G, Yuan J, Chen J, Huang J. 2010a. FAN1 acts with FANCI-FANCD2 to promote DNA interstrand cross-link repair. Science 329: 693-696.

Liu Y, Fang Y, Shao H, Lindsey-Boltz L, Sancar A, Modrich P. 2010b. Interactions of human mismatch repair proteins MutS $\alpha$ and MutL $\alpha$ with proteins of the ATR-Chk1 pathway. J Biol Chem 285: 5974-5982. 
López de Saro FJ, Marinus MG, Modrich P, O’Donnell M. 2006. The beta sliding clamp binds to multiple sites within MutL and MutS. J Biol Chem 281: 14340-14349.

Lucchini R, Wellinger RE, Sogo JM. 2001. Nucleosome positioning at the replication fork. EMBO J 20: 7294-7302.

Lynch HT, Lynch PM, Lanspa SJ, Snyder CL, Lynch JF, Boland CR. 2009. Review of the Lynch syndrome: History, molecular genetics, screening, differential diagnosis, and medicolegal ramifications. Clin Genet 76: 1-18.

MacKay C, Déclais AC, Lundin C, Agostinho A, Deans AJ MacArtney TJ, Hofmann K, Gartner A, West SC, Helleday T, et al. 2010. Identification of KIAA1018/FAN1, a DNA repair nuclease recruited to DNA damage by monoubiquitinated FANCD2. Cell 142: 65-76.

Malkov VA, Biswas I, Camerini-Otero RD, Hsieh P. 1997. Photocross-linking of the NH2-terminal region of Taq MutS protein to the major groove of a heteroduplex DNA. J Biol Chem 272: 23811-23817.

Martik D, Baitinger C, Modrich P. 2004. Differential specificities and simultaneous occupancy of human MutSa nucleotide binding sites. J Biol Chem 279: 28402-28410.

Martinez SL, Kolodner RD. 2010. Functional analysis of human mismatch repair gene mutations identifies weak alleles and polymorphisms capable of polygenic interactions. Proc Natl Acad Sci 107: 5070-5075.

Matson SW, Robertson AB. 2006. The UvrD helicase and its modulation by the mismatch repair protein MutL. $\mathrm{Nu}$ cleic Acids Res 34: 4089-4097.

Mazur DJ, Mendillo ML, Kolodner RD. 2006. Inhibition of Msh6 ATPase activity by mispaired DNA induces a Msh2(ATP)-Msh6(ATP) state capable of hydrolysis-independent movement along DNA. Mol Cell 22: 39-49.

Mazurek A, Johnson CN, Germann MW, Fishel R. 2009. Sequence context effect for hMSH2-hMSH6 mismatchdependent activation. Proc Natl Acad Sci 106: $4177-$ 4182.

McMurray CT. 2008. Hijacking of the mismatch repair system to cause CAG expansion and cell death in neurodegenerative disease. DNA Repair 7: 1121-1134.

McNally R, Bowman GD, Goedken ER, O'Donnell M, Kuriyan J. 2010. Analysis of the role of PCNA-DNA contacts during clamp loading. BMC Struct Biol 10: 3 .

Mendillo ML, Mazur DJ, Kolodner RD. 2005. Analysis of the interaction between the Saccharomyces cerevisiae MSH2-MSH6 and MLH1-PMS1 complexes with DNA using a reversible DNA end-blocking system. J Biol Chem 280: 22245-22257.

Mendillo ML, Hargreaves VV, Jamison JW, Mo AO, Li S, Putnam CD, Woods VL, Kolodner RD. 2009. A conserved MutS homolog connector domain interface interacts with MutL homologs. Proc Natl Acad Sci 106: $22223-$ 22228.

Mendillo ML, Putnam CD, Mo AO, Jamison JW, Li S, Woods VL, Kolodner RD. 2010. Probing DNA- and ATP-mediated conformational changes in the MutS family of mispair recognition proteins using deuterium exchange mass spectrometry. J Biol Chem 285: 1317013182.

Modrich P, Lahue R. 1996. Mismatch repair in replication fidelity, genetic recombination, and cancer biology. Annu Rev Biochem 65: 101-133.
Mojas N, Lopes M, Jiricny J. 2007. Mismatch repair-dependent processing of methylation damage gives rise to persistent single-stranded gaps in newly replicated DNA. Genes Dev 21: 3342-3355.

Monti MC, Cohen SX, Fish A, Winterwerp HHK, Barendregt A, Friedhoff P, Perrakis A, Heck AJR, Sixma TK, van den Heuvel RHH, et al. 2011. Native mass spectrometry provides direct evidence for DNA mismatch-induced regulation of asymmetric nucleotide binding in mismatch repair protein MutS. Nucleic Acids Res 39: 8052-8064.

Natrajan G, Lamers MH, Enzlin JH, Winterwerp HHK, Perrakis A, Sixma TK. 2003. Structures of Escherichia coli DNA mismatch repair enzyme MutS in complex with different mismatches: A common recognition mode for diverse substrates. Nucleic Acids Res 31: 48144821.

Nick McElhinny SA, Kissling GE, Kunkel TA. 2010. Differential correction of lagging-strand replication errors made by DNA polymerases $\alpha$ and $\delta$. Proc Natl Acad Sci 107: 21070-21075.

Nishant KT, Plys AJ, Alani E. 2008. A mutation in the putative MLH3 endonuclease domain confers a defect in both mismatch repair and meiosis in Saccharomyces cerevisiae. Genetics 179: 747-755.

Obmolova G, Ban C, Hsieh P, Yang W. 2000. Crystal structures of mismatch repair protein MutS and its complex with a substrate DNA. Nature 407: 703-710.

Owen BAL, H Lang W, McMurray CT. 2009. The nucleotide binding dynamics of human MSH2-MSH3 are lesion dependent. Nat Struct Mol Biol 16: 550-557.

Papaioannou I, Simons JP, Owen JS. 2012. Oligonucleotidedirected gene-editing technology: Mechanisms and future prospects. Expert Opin Biol Ther 12: 329-342.

Pavlov YI, Mian IM, Kunkel TA. 2003. Evidence for preferential mismatch repair of lagging strand DNA replication errors in yeast. Curr Biol 13: 744-748.

Peltomäki P. 2012. Mutations and epimutations in the origin of cancer. Exp Cell Res 318: 299-310.

Peña-Diaz J, Jiricny J. 2012. Mammalian mismatch repair: Error-free or error-prone? Trends Biochem Sci 37: 206214.

Peña-Diaz J, Bregenhorn S, Ghodgaonkar M, Follonier C, Artola-Borán M, Castor D, Lopes M, Sartori AA, Jiricny J. 2012. Noncanonical mismatch repair as a source of genomic instability in human cells. Mol Cell 47: 669-680.

Peng M, Litman R, Xie J, Sharma S, Brosh RM, Cantor SB. 2007. The FANCJ/MutL $\alpha$ interaction is required for correction of the cross-link response in FA-J cells. EMBO J 26: $3238-3249$.

Pillon MC, Lorenowicz JJ, Uckelmann M, Klocko AD, Mitchell RR, Chung YS, Modrich P, Walker GC, Simmons LA, Friedhoff P, et al. 2010. Structure of the endonuclease domain of MutL: Unlicensed to cut. Mol Cell 39: 145-151.

Pillon MC, Miller JH, Guarné A. 2011. The endonuclease domain of MutL interacts with the $\beta$ sliding clamp. DNA Repair 10: 87-93.

Pinto AV, Mathieu A, Marsin S, Veaute X, Ielpi L, Labigne A, Radicella JP. 2005. Suppression of homologous and 
J. Jiricny

homeologous recombination by the bacterial MutS2 protein. Mol Cell 17: 113-120.

Plotz G, Welsch C, Giron-Monzon L, Friedhoff P, Albrecht M, Piiper A, Biondi RM, Lengauer T, Zeuzem S, Raedle J. 2006. Mutations in the MutS $\alpha$ interaction interface of MLH1 can abolish DNA mismatch repair. $\mathrm{Nu}$ cleic Acids Res 34: 6574-6586.

Pluciennik A, Modrich P. 2007. Protein roadblocks and helix discontinuities are barriers to the initiation of mismatch repair. Proc Natl Acad Sci 104: 12709-12713.

Pluciennik A, Burdett V, Lukianova O, O’Donnell M, Modrich P. 2009. Involvement of the $\beta$ clamp in methyldirected mismatch repair in vitro. $J$ Biol Chem 284: 32782-32791.

Pluciennik A, Dzantiev L, Iyer RR, Constantin N, Kadyrov FA, Modrich P. 2010. PCNA function in the activation and strand direction of MutL $\alpha$ endonuclease in mismatch repair. Proc Natl Acad Sci 107: 16066-16071.

Qiu R, Derocco VC, Harris C, Sharma A, Hingorani MM Erie DA, Weninger KR. 2012. Large conformational changes in MutS during DNA scanning, mismatch recognition, and repair signalling. EMBO J 31: 2528-2540.

Raevaara TE, Korhonen MK, Lohi H, Hampel H, Lynch E, Lönnqvist KE, Holinski-Feder E, Sutter C, McKinnon W, Duraisamy S, et al. 2005. Functional significance and clinical phenotype of nontruncating mismatch repair variants of MLH1. Gastroenterology 129: 537-549.

Räschle $M$, Marra G, Nyström-Lahti $M$, Schär P, Jiricyn J. 1999. Identification of hMutL $\beta$, a heterodimer of hMLH1 and hPMS1. J Biol Chem 274: 32368-32375.

Räschle M, Dufner P, Marra G, Jiricny J. 2002. Mutations within the hMLH1 and hPMS2 subunits of the human MutL $\alpha$ mismatch repair factor affect its ATPase activity, but not its ability to interact with hMutS $\alpha$. J Biol Chem 277: $21810-21820$.

Rodriguez GP, Romanova NV, Bao G, Rouf NC, Kow YW, Crouse GF. 2012. Mismatch repair-dependent mutagenesis in nondividing cells. Proc Natl Acad Sci 109: $6153-$ 6158.

Russo MT, Blasi MF, Chiera F, Fortini P, Degan P, Macpherson P, Furuichi M, Nakabeppu Y, Karran P, Aquilina G, et al. 2004. The oxidized deoxynucleoside triphosphate pool is a significant contributor to genetic instability in mismatch repair-deficient cells. Mol Cell Biol 24: 465-474.

Russo MT, De Luca G, Casorelli I, Degan P, Molatore S, Barone F, Mazzei F, Pannellini T, Musiani P, Bignami M. 2009. Role of MUTYH and MSH2 in the control of oxidative DNA damage, genetic instability, and tumorigenesis. Cancer Research 69: 4372-4379.

Sachadyn P. 2010. Conservation and diversity of MutS proteins. Mutat Res 694: 20-30.

Sacho EJ, Kadyrov FA, Modrich P, Kunkel TA, Erie DA. 2008. Direct visualization of asymmetric adenine-nucleotideinduced conformational changes in MutL $\alpha$. Mol Cell 29: $112-121$.

Santucci-Darmanin S, Neyton S, Lespinasse F, Saunières A, Gaudray P, Paquis-Flucklinger V. 2002. The DNA mismatch-repair MLH3 protein interacts with MSH4 in meiotic cells, supporting a role for this MutL homolog in mammalian meiotic recombination. Hum Mol Genet 11: $1697-1706$.
Schöpf B, Bregenhorn S, Quivy J-P, Kadyrov FA, Almouzni G, Jiricny J. 2012. Interplay between mismatch repair and chromatin assembly. Proc Natl Acad Sci 109: 1895-1900.

Shell SS, Putnam CD, Kolodner RD. 2007a. Chimeric Saccharomyces cerevisiae Msh6 protein with an Msh3 mispair-binding domain combines properties of both proteins. Proc Natl Acad Sci 104: 10956-10961.

Shell SS, Putnam CD, Kolodner RD. 2007b. The N terminus of Saccharomyces cerevisiae Msh6 is an unstructured tether to PCNA. Mol Cell 26: 565-578.

Simmons LA, Davies BW, Grossman AD, Walker GC. 2008. $\beta$ clamp directs localization of mismatch repair in Bacillus subtilis. Mol Cell 29: 291-301.

Smogorzewska A, Desetty R, Saito TT, Schlabach M, Lach FP, Sowa ME, Clark AB, Kunkel TA, Harper JW, Colaiácovo MP, et al. 2010. A genetic screen identifies FAN1, a Fanconi anemia-associated nuclease necessary for DNA interstrand crosslink repair. Mol Cell 39: 36-47.

Snowden T, Acharya S, Butz C, Berardini M, Fishel R. 2004. hMSH4-hMSH5 recognizes Holliday Junctions and forms a meiosis-specific sliding clamp that embraces homologous chromosomes. Mol Cell 15: 437-451.

Snowden T, Shim K-S, Schmutte C, Acharya S, Fishel R. 2008. hMSH4-hMSH5 adenosine nucleotide processing and interactions with homologous recombination machinery. J Biol Chem 283: 145-154.

Stojic L, Brun R, Jiricny J. 2004. Mismatch repair and DNA damage signalling. DNA Repair 3: 1091-1101.

Studamire B, Quach T, Alani E. 1998. Saccharomyces cerevisiae Msh2p and Msh6p ATPase activities are both required during mismatch repair. Mol Cell Biol 18: 75907601.

Su SS, Modrich P. 1986. Escherichia coli MutS-encoded protein binds to mismatched DNA base pairs. Proc Natl Acad Sci 83: 5057-5061.

Su SS, Lahue RS, Au KG, Modrich P. 1988. Mispair specificity of methyl-directed DNA mismatch correction in vitro. J Biol Chem 263: 6829-6835.

Sugawara N, Pâques F, Colaiácovo M, Haber JE. 1997. Role of Saccharomyces cerevisiae Msh2 and Msh3 repair proteins in double-strand break-induced recombination. Proc Natl Acad Sci 94: 9214-9219.

Surtees JA, Alani E. 2006. Mismatch repair factor MSH2MSH3 binds and alters the conformation of branched DNA structures predicted to form during genetic recombination. J Molec Biol 360: 523-536.

Surtees JA, Argueso JL, Alani E. 2004. Mismatch repair proteins: Key regulators of genetic recombination. Cytogenet Genome Res 107: 146-159.

Thomas DC, Roberts JD, Kunkel TA. 1991. Heteroduplex repair in extracts of human HeLa cells. J Biol Chem 266: 3744-3751.

Tian L, Gu L, Li G-M. 2009. Distinct nucleotide binding/ hydrolysis properties and molar ratio of MutS $\alpha$ and MutS $\beta$ determine their differential mismatch binding activities. J Biol Chem 284: 11557-11562.

Tran PT, Erdeniz N, Symington LS, Liskay RM. 2004. EXO1A multi-tasking eukaryotic nuclease. DNA Repair 3: 1549-1559. 
Trojan J, Zeuzem S, Randolph A, Hemmerle C, Brieger A, Raedle J, Plotz G, Jiricny J, Marra G. 2002. Functional analysis of hMLH1 variants and HNPCC-related mutations using a human expression system. Gastroenterology 122: $211-219$.

Umar A, Buermeyer AB, Simon JA, Thomas DC, Clark AB, Liskay RM, Kunkel TA. 1996. Requirement for PCNA in DNA mismatch repair at a step preceding DNA resynthesis. Cell 87: 65-73.

Wanat JJ, Singh N, Alani E. 2007. The effect of genetic background on the function of Saccharomyces cerevisiae $\mathrm{mlh}$ alleles that correspond to HNPCC missense mutations. Hum Mol Genet 16: 445-452.

Wang H, Hays JB. 2003. Mismatch repair in human nuclear extracts: Effects of internal DNA-hairpin structures between mismatches and excision-initiation nicks on mismatch correction and mismatch-provoked excision. J Biol Chem 278: 28686-28693.

Wang H, Hays JB. 2004. Signaling from DNA mispairs to mismatch-repair excision sites despite intervening blockades. EMBO J 23: 2126-2133.

Wang Y, Cortez D, Yazdi P, Neff N, Elledge SJ, Qin J. 2000. BASC, a super complex of BRCA1-associated proteins involved in the recognition and repair of aberrant DNA structures. Genes Dev 14: 927-939.

Warbrick E. 2006. A functional analysis of PCNA-binding peptides derived from protein sequence, interaction screening, and rational design. Oncogene 25: 2850-2859.

Warren JJ, Pohlhaus TJ, Changela A, Iyer RR, Modrich PL, Beese LS. 2007. Structure of the human MutS $\alpha$ DNA lesion recognition complex. Mol Cell 26: 579-592.

Wimmer K, Etzler J. 2008. Constitutional mismatch repairdeficiency syndrome: Have we so far seen only the tip of an iceberg? Hum Genet 124: 105-122.

Winkler I, Marx AD, Lariviere D, Heinze RJ, Cristóvão M, Reumer A, Curth U, Sixma TK, Friedhoff P. 2011. Chemical trapping of the dynamic MutS-MutL complex formed in DNA mismatch repair in Escherichia coli. J Biol Chem 286: 17326-17337.

Wu S-Y, Culligan K, Lamers M, Hays J. 2003. Dissimilar mispair-recognition spectra of Arabidopsis DNAmismatch-repair proteins $\mathrm{MSH} 2{ }^{*} \mathrm{MSH} 6$ (MutS $\alpha$ ) and MSH2*MSH7 (MutSy). Nucleic Acids Res 31: 60276034.

York SJ, Modrich P. 2006. Mismatch repair-dependent iterative excision at irreparable O6-methylguanine lesions in human nuclear extracts. J Biol Chem 281: 22674-22683.

Yoshikiyo K, Kratz K, Hirota K, Nishihara K, Takata M, Kurumizaka H, Horimoto S, Takeda S, Jiricny J. 2010. KIAA1018/FAN1 nuclease protects cells against genomic instability induced by interstrand cross-linking agents. Proc Natl Acad Sci 107: 21553-21557.

Yoshioka KI, Yoshioka Y, Hsieh P. 2006. ATR kinase activation mediated by MutS $\alpha$ and MutL $\alpha$ in response to cytotoxic $O^{6}$-methylguanine adducts. Mol Cell 22: 501510.

Zhai J, Hingorani MM. 2010. Saccharomyces cerevisiae Msh2-Msh6 DNA binding kinetics reveal a mechanism of targeting sites for DNA mismatch repair. Proc Natl Acad Sci 107: 680-685.

Zhang Y, Yuan F, Presnell SR, Tian K, Gao Y, Tomkinson AE, Gu L, Li G-M. 2005. Reconstitution of 5' -directed human mismatch repair in a purified system. Cell 122: 693-705.

Zhou W, Otto EA, Cluckey A, Airik R, Hurd TW, Chaki M, Diaz K, Lach FP, Bennett GR, Gee HY, et al. 2012. FAN1 mutations cause karyomegalic interstitial nephritis, linking chronic kidney failure to defective DNA damage repair. Nat Genet 44: 910-915.

Zlatanou A, Despras E, Braz-Petta T, Boubakour-Azzouz I, Pouvelle C, Stewart GS, Nakajima S, Yasui A, Ishchenko AA, Kannouche PL. 2011. The hMsh2-hMsh6 complex acts in concert with monoubiquitinated PCNA and Pol $\eta$ in response to oxidative DNA damage in human cells. Mol Cell 43: 649-662. 


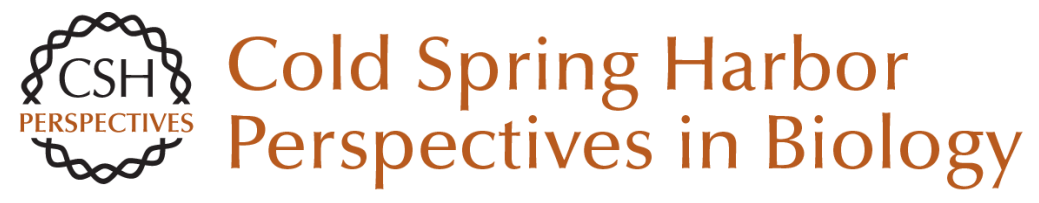

\section{Postreplicative Mismatch Repair}

Josef Jiricny

Cold Spring Harb Perspect Biol 2013; doi: 10.1101/cshperspect.a012633

Subject Collection DNA Repair, Mutagenesis, and Other Responses to DNA Damage

DNA Repair by Reversal of DNA Damage Chengqi Yi and Chuan He

Replicating Damaged DNA in Eukaryotes Nimrat Chatterjee and Wolfram Siede

DNA Damage Sensing by the ATM and ATR

Kinases

Alexandre Maréchal and Lee Zou

Repair of Strand Breaks by Homologous

Recombination

Maria Jasin and Rodney Rothstein

Advances in Understanding the Complex Mechanisms of DNA Interstrand Cross-Link

Repair

Cheryl Clauson, Orlando D. Schärer and Laura Niedernhofer

Ancient DNA Damage

Jesse Dabney, Matthias Meyer and Svante Pääbo

DNA Damage Response: Three Levels of DNA Repair Regulation

Bianca M. Sirbu and David Cortez

Alternative Excision Repair Pathways Akira Yasui
DNA Repair by Reversal of DNA Damage Chengqi Yi and Chuan He

Translesion DNA Synthesis and Mutagenesis in

Prokaryotes Robert P. Fuchs and Shingo Fujii

Nucleosome Dynamics as Modular Systems that Integrate DNA Damage and Repair Craig L. Peterson and Genevieve Almouzni

DNA Damage Responses in Prokaryotes:

Regulating Gene Expression, Modulating Growth

Patterns, and Manipulating Replication Forks Kenneth N. Kreuzer

Nucleotide Excision Repair in Eukaryotes Orlando D. Schärer

Biology of Extreme Radiation Resistance: The

Way of Deinococcus radiodurans Anita Krisko and Miroslav Radman

Mammalian Transcription-Coupled Excision

Repair

Wim Vermeulen and Maria Fousteri

DNA Repair at Telomeres: Keeping the Ends Intact Christopher J. Webb, Yun Wu and Virginia A. Zakian

For additional articles in this collection, see http://cshperspectives.cshlp.org/cgi/collection/

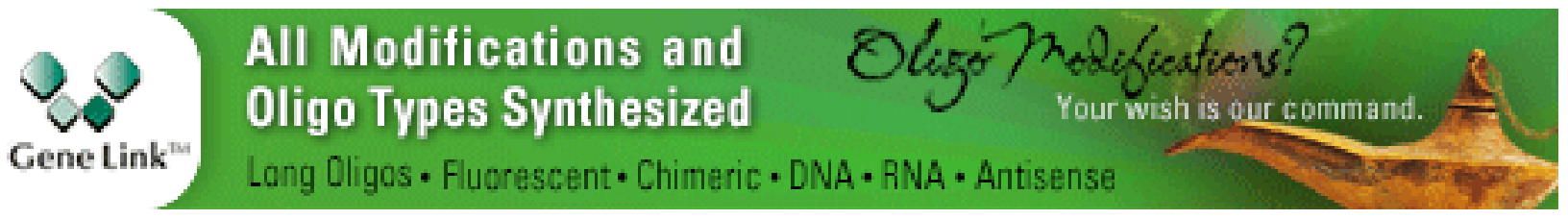

Copyright @ 2013 Cold Spring Harbor Laboratory Press; all rights reserved 